\title{
ÜBER DIE DIATOMEENFLORA DES BOTTNISCHEN MEERBUSENS UND DER OSTSEE
}

von

KARL MÖLDER

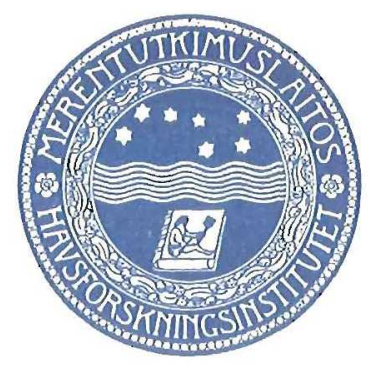

HELSINKI 1962 


\title{
UBER DIE DIATOMEENFLORA DES BOTTNISCHEN MEERBUSENS \\ UND DER OSTSEE
}

\author{
von \\ KARL MÖLDER
}

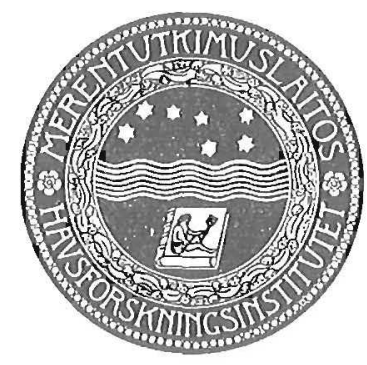

HELSINKI 1962 
Helsinki 1962. Valtionenroston kitjapnino 


\section{Vorwort}

Im Sommer 1958, als 》ARANDA», das Schiff des Instituts für Meeresforschung in Finland, seine Forschungsreise im Bottnischen Meerbusen und im Balttischen Meere durchfühnte, sammelte Herr Mag. phil. N-O. Laurell auf dieser Reise für mich Diatomeenproben an denselben Stellen, wo das Institut für Meeresforschung seine Wasserproben für chemische Analysen entnahm. Die Planktonproben wurden mit dem Planktonnetz zwischen $15 \mathrm{~m}$ Tiefe und der Oberfläche des Wassers und die Benthosproben wiederum am Meeresboden entnommen; diese enthielten teils lebende, teils eingegangene Diatomeen. Die Diatomeenproben wurden gleich mit Formalin dionserviert und danach im Laboratorium aus ihnen Dauerpräparate hergestellt. Aus diesen Präparaten wurden clamn die Diatomeen quantitativ untersucht. Die Ergebnisse sind in dieser Arbeit wieclergegeben.

Herm. Mag. phil. N-O. Laurell möchte ich meinen besten Dank clafür aussjpechen, dass er mir mit grosser Sorgfalt und Kenntmis aus dem Bottnischen Meerbusen, dem Finnischen Meerbusen sowie der Ostsee Diatomeenproben eingebracht hat. Die wirtschaftliche Seite meiner Forschungsarbeit ist durch ein von der Staatlichen Naturwissenschaftlichen Kommission hewilligtes Stipendium ermöglicht worden, wofür ich meinen besten Dank zum Ausdruck bringen möchte.

Tapiola 1962.

Der: Verfasser" 
. 


\section{Inhaltsverzeichnis}

seise

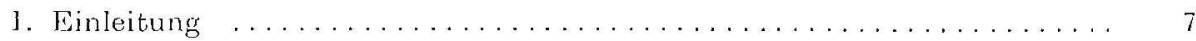

II. Salzgehalt und 'Temperatur des Untersuchungsgebietes ........... 9

III. Über die Methodik der Diatomeenuntersuchungen $\ldots \ldots \ldots \ldots \ldots \ldots$. 16

IV. Planktondiatomeen des Untersuchungsgebietes $\ldots \ldots \ldots \ldots \ldots \ldots \ldots 21$

1. Bottnischer Meerbusen ......................... 21

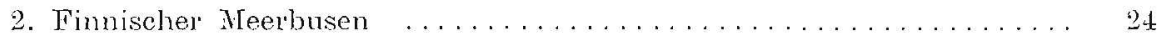

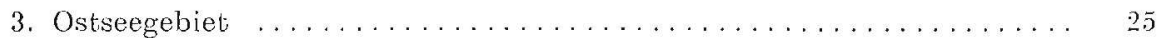

$\Upsilon$. Abhängigkeit rler ökologischen Planktondiatomeengl'uppen von der Salzkonzentration des Wasser's ...................... 28

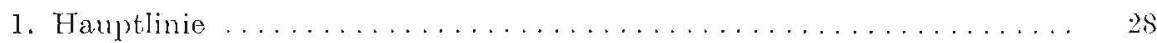

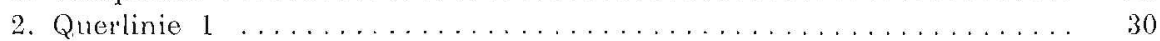

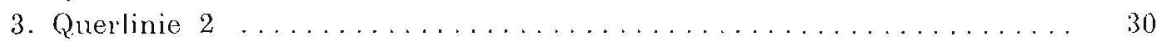

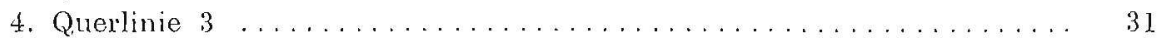

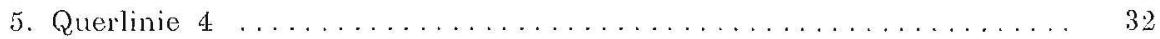

6. Planktondiatomeen in der Umgebung der Insel Gotland ......... 3.

VY. Verbreitung der Planktondiatomeen im Untersuchungsgebiet . . . . . . . 34

1. Bottnischer Meerbusen ......................... 3.5

2. Finnischer Meerbusen ........................... 36

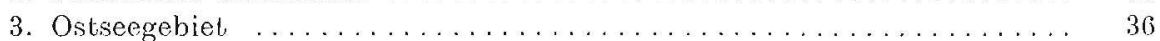

VII. Auf dem Meeresboden des Untersuchungsgebietes vorkommende Diatomeen ....................................... 38

1. Bottnischer Meerbusen ........................... 38

2. Finnischer Meerbusen ........................... 39

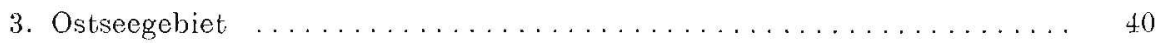

VIII. Abhängigkeit der am Meeresboden vorkommenden ökologischen Diatomeengruppen von der Salzkonzentration des Wassers ............. 48

IX. Verbreitung der Benthosdiatomeen im Untersuchungsgebiet......... $5 \mathrm{l}$

x. Vergleich zwischen Plankton- und Benthosdiatomeen ........... 54

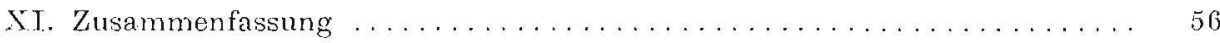

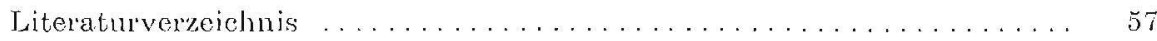





\section{Einleitung}

Obgleich Juhlin-Dannfigt 1882 seine Untersuchung "On the Diatoms of the Baltic Sea) veröffentlicht hat, wissen wir über die Diatomeenflora der Ostsee wie auch der des Finnischen und des Bottnischen Meerbusens sehr wenig. UUber das Plankton des offenen Meeres fehlen Untersuchungen völlig, ebensowenig haben wir eine Vorstellung von den Benthosdiatomeen grösserer Tiefen. Diese Lücke versucht die vorliegende Untersuchung teilweise auszufüllen.

Über die Diatomeen des Ostseegebietos liegen mehrere Untersuchungen vor. Genannt seien die Arbeiten von Aurivillius (1886) "Das Plankton des Ba.ltischen Meeres», P. T. CLeve (1905) "On the Plankton of the coast stations Måseskär and Väderöbod, collected during August 1902-July 1903 and the seasonal variations of the Baltic currenty, Astrid CLeve-Eucker (1910) "Das Bacillariaceenplanliton in Gewässern bei Stockholm", (1912) "Das Bacillariaceenplankton in Gewässern bei Stockholm II", Levander (1915) "Zur Kenntnis der Bodenfauna und des Planktons der Pojoviek», LEEGAARD (1920) »Microplankton from the Finnish Waters during the month of May 1919», Schulz (1926) "Die Kieselalgen der Danziger Bucht», VäLImaNGAS (1926) "Planktologische Untersuchungen im Hafengebiet von Helsingfor's», WILLER (1931) "Vergleichende Untersuchungen an Strandgewässern", VÄLIKANGAS (1933) „Uber die Biologie der Ostsee als Brackwassergebiet», MöLDER (1943 a und b) "Studien über die Ölkologie und Geologie der Bodendia.tomeen in der Pojo-Bucht», »Rezente Diatomeen in Finnland als Grundlage quartärgeologischer Untersuchungen», HALMT (1944) "Planktologische Untersuchungen in der Pojo-Bucht und angrenzenden Gewässem T», Hatme und MötDer (1958) »Planktologische Untersuchungen in der Pojo-Bucht und angrenzenden Gewässern", Stronsses (1959 und 1960) "Neue Diatomeen aus cler Ostsee I und Neue Diatomeen aus der Ostsee II».

Wie aus dem Obigen hervorgeht, behandeln alle angeführten Untersuchungen nur die Ufergebiete, und hauptsächlich auch nur Benthosdiatomeen, die in diesen Gegenden reichlich vorkommen. Von den Planktondiatomeen sind Actinocychus elirenbergii, Chatoceros- und coscinodiscus-Arten, Skeletonema coslatum und Thalassiosira baltica Formen, die häufig in 
den Diatomeenproben vorkommen. Auch findet man im Plankton in C Cernähe viel mehr Arten und Varietäten als im offenen Meer. So konnte der Verfasser dieser Untersuchung im Plankton der Pojo-Bucht insgesamt 502 Arten, Varietäten und Formen feststellen, während im Plankton dieser Untersuchung nur 51 Formen enthalten waren. In den anderen Untersuchungen, die in Ufernähe ausgeführt worden sind, kommen im Plankiton sehr viele Diatomeenformen vor.

In den Planktonproben aus dem offenen Neere erscheinen die Planlztondiatomeen sehr artenarm und Benthosformen fehlen völlig. Die Artenund Varietätenzahl schwankten zwischen 4 und 10 und häufiger kamen Thalassiosira ballica, Actinocyclus ehrenbergii, Chaetoceros danicus und Ch. wighamii vor. So treten in Bottnischen Meerbusen insgesamt 30, im Finnischen Meerbusen 30 und in der Ostsee 29 Arten und Varietäten auf oder in allen obengenannten Gebieten insgesamt nur $5 \mathrm{l}$ Formen. Auch unter diesen Diatomeen gibt es fermer Arten, clie in Untersuchungsgebiet im allgemeinen nicht wachsen, sondern von den Flüssen dorthin verschleppt verden. Von diesen Formen sind zu nenmen: Melosira granulata, M. juergensii, Tabellaria fenestrata, T. flocculosa, Asterionella formosa, Rhoicosphenia curvata, Diatoma elongatum, Navicula gastrum, N. Lundströmi, Nitzshia capitellata, $N$. subcapitellata und Symedra tabulata oder insgesamt 12 Formen, die nicht zu den Planktondiatomeen der Ostsee gehören. So bleiben nur 39 Diatomeenformen übrig, die das Plankton der Ostsee und des Bottnischen Meerbusens bilden und individuenreich vorkommen. 


\section{Salzgelıalt und Temperatur des Untersuchungsgebietes}

Im Jahre 1955 veröfentlichte GRANQVIST über die Ostsee eine Untersuchung, in der er auch eine Karte über die Salzkonzentration des Wassers darstellt. Aus dieser Karte (Abb. 1) geht hervor, dass das Wasser am Nordende des Bottnischen Meerbusens weniger als $2.5 \%$ Salz enthält. Das Wasser enthält clort wahrscheinlich cleshalb so wenig Salz, weil die Flüsse Torniojoki und Kemijolki in das Nordende des Meerbusens münden. Schon bei der Staclt Kemi steigt die Salzkonzentration auf $3 \%$, und bei der Stadt Oulu ist der: Salzkehalt schon 3.5\% \% Etwas nördlich der Tnseln Björkö und Raipalıoto ist die Salzkonzentiation $4 \%$, und bei der Stadt Vaasa steigt sie schon auf $5 \%$. Zwischen der Stadt Vaasa und den Insehn Ahvenanmaa (Aland) vermehrt sich die Salzkonzentration des Wassers auf $6 \%$, und erst südlich der Inseln erreicht sie $6.5 \%$. Tn der Umgebung cler Insel Gotland enthält das Wasser $7 \%$, und von der Südspitze der Insel Gotland südwärts steigt die Salzkonzentration auf $7.5 \%$.

Während seiner Forschungsreise mit dem Schiff "ARANDA" hat das Institut für Meeresforschung in Finmland clie Wasserproben an denselben Stellen entnommen, wo die Diatomeenproben gesammelt worden sind. Auch ist die Temperatur gemessen und sind alle Ergebnisse in der Zs. Merentutkimuslaitolssen julkaisu Nr 193 im Jahre 1959 veröffentlicht worden. Nach den obengenannten Resultaten hat der Verfasser ein Diagramm (Abb. 2) dargestellt. Wiedergegeben sind die Salzkonzentretion des Oberflächenwassers, aus dem die Planktondiatomeen gesammelt worden sind, Salzkonzentration des Wassers am Meeresboden, wo die Benthosdiatomeen entnommen worden sind, und ausserdem die Wassertemperatur des Oberflächenwassers sowie des Wasser's auf dem Meeresgrun.

Die Salzkonzentration war am 15. Juni 1958 bei Station 1 (F2 nach dem Institut für Meeresforschung) in $0 \mathrm{~m}$ Tiefe $2.63 \%$ und in $105 \mathrm{~m}$ Tiefe $3.91 \%$ (Abb. 2). Die Wassertemperatur war an clemselben Tage in $0 \mathrm{~m}$ Tiefe $8^{\circ} \mathrm{C}$ und in $105 \mathrm{~m}$ Tiefe $1.47^{\circ} \mathrm{C}$. Die Salzkonzentration steigt, and die Temperatur fällt am Meeresboden deutlich.

Bei der Station 2 (F 12) ist die Salzkonzentration schon in Oberflächenwasser $3.68 \%$ und am Meeresboden in $109 \mathrm{~m}$ Tiefe $4.54 \%$. Die Tem-

$2 \quad 35.54-62$ 


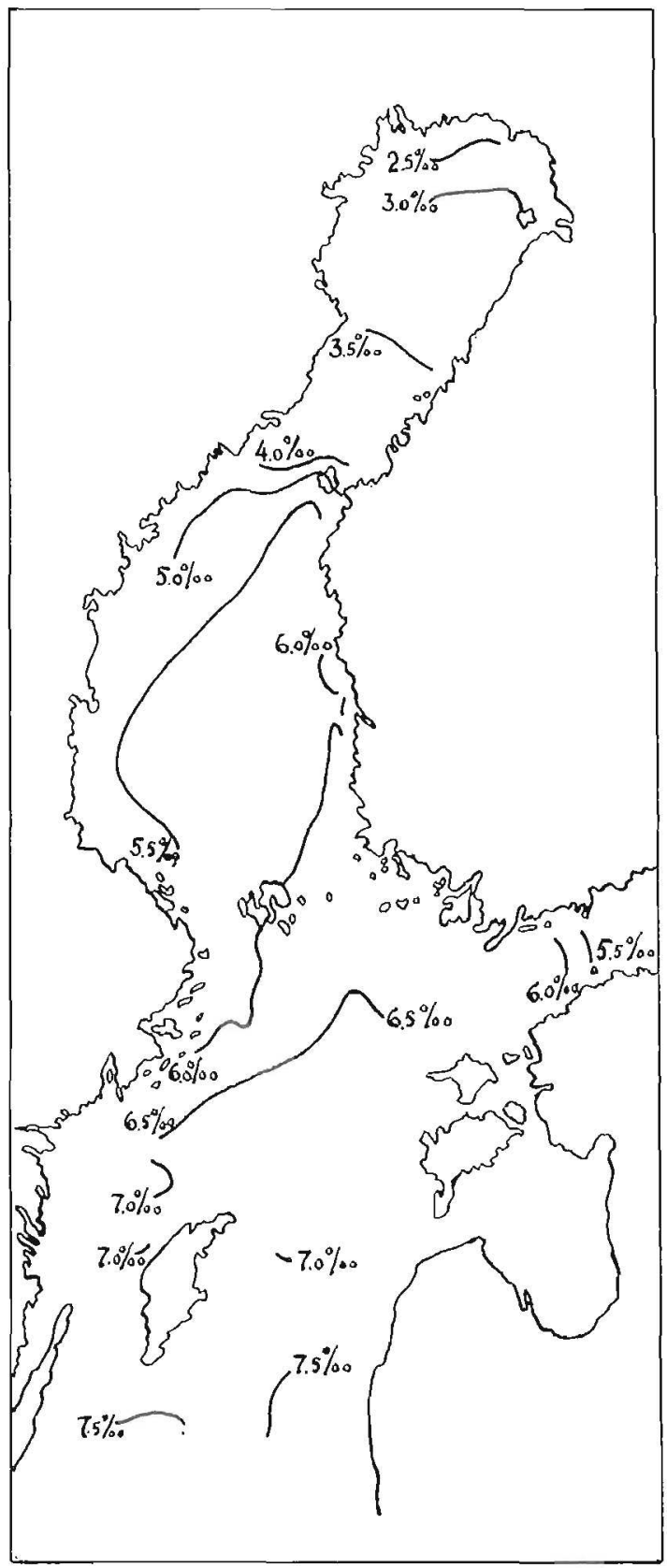

Abbildung 1. Salzkonzentrationen des Wassers in der Ostsee (Nach Granquist) 


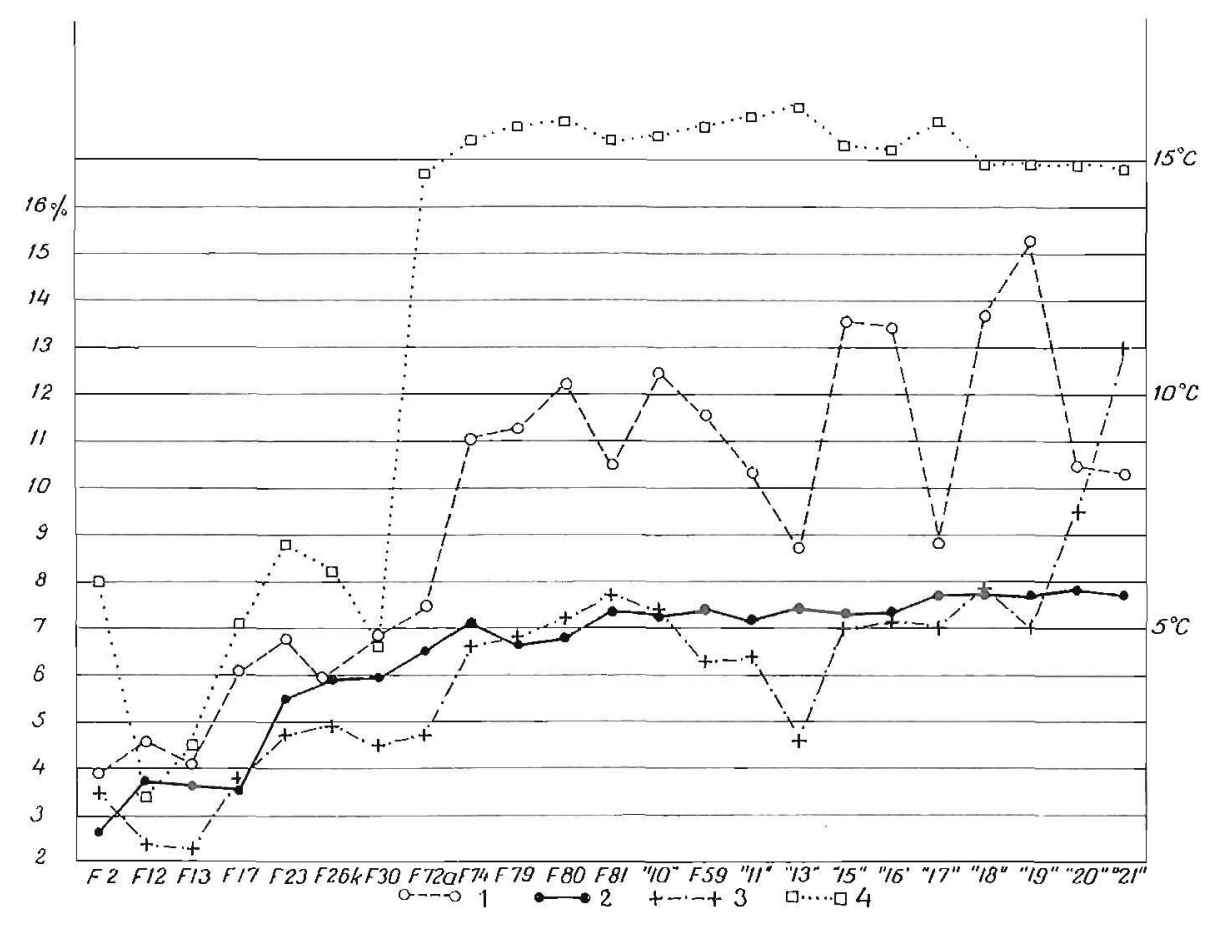

Abbildung 2. Salzonzentrationen der Ostsee im Jahre 1958 (Nach Koroleff). 1. Silzgehalt des Wassers auf dem Meeresboclen. 2. Salzgehalt des Oberflächonwasser's. 3. T'enperatul des Wassers aut dem Meeresboden. 4. Temperatur des Oberflächenwassers.

peratur war am 14 Juni in $0 \mathrm{~m}$ Tiefe nur $1.40^{\circ} \mathrm{C}$ und in $109 \mathrm{~m}$ Tiefe $0.39^{\circ} \mathrm{C}$. Der Salzkehalt bei dieser Station ist deutlich grösser als bei Station 1, die 'Temperatur wiederum viel niedriger. Wahrscheinlich hängen diese grossen Unterschiede zwischen den Stationen 1 und 2 davon ab, dass mehrere grössere Flüsse, wie z. B. Torniojoki, Kemijoki, Oulujoki u. a., in den Meerbusen münden.

Bei Station 3 (F 13) beläuft sich die Salzkonzentration im Oberflä.chenwasser auf $3.04 \%$ und am Meeresboden in $60 \mathrm{~m}$ Tiefe auf $4.09 \%$, die Wassertemperatur wieclerum beträgt 2.46 und $0.26^{\circ} \mathrm{C}$. Die Unterschiede zwischen den Stationen 2 und 3 sind eigentlich sehr gering, oder das Wasser ist an beiden Stellen beinahe ähnlich.

Bei der Station 4 (F 17) ist die Salzkonzentration im Oberflächenwasser $3.57 \%$ und in $60 \mathrm{~m}$ Tiefe am Meeresboden $6.08 \%$. Die Temperatur des Oberflächenwassers betrug am 14 Juni $5.12^{\circ} \mathrm{C}$ und am Meeresboden in $60 \mathrm{~m}$ Tiefe nur $1.77^{\circ} \mathrm{C}$. Bei dieser Station ist die Salzlzonzentration am Meeresboden gestiegen, aber im Oberflächenwasser ist kein Unterschied 
festzustellen. Auch die Temperatur des Wassers ist schon grösser als bei den Stationen 2 und 3 (Abb. 1 und 2).

Bei Station 5 (F 23) steigt die Salzkonzentration im Oberflächenwasser schon auf $5.50 \%$ und in $130 \mathrm{~m}$ Tiefe am Meeresboden auf $6.7+\%$. Die Wassertemperatur war am $13 \mathrm{Juni}$ an der Oberfläche $6.82^{\circ} \mathrm{C}$ und am Meeresboden in $130 \mathrm{~m}$ Tiefe $2.70^{\circ} \mathrm{C}$. Wie aus Abb. 2 ersichtlich, steigt die Salzkonzentration bei clieser Station recht beträ.chtlich. Auch ist aus den Temperaturangaben des Instituts für Meeresforschung (1959) zu ersehen, dass die Temperatur des Wassers in $40-70 \mathrm{~m}$ Tiefe nur 0.60 und $0.91^{\circ} \mathrm{C}$ beträgt und erst mit zunehmen der Tiefe auf $2.70^{\circ} \mathrm{C}$ steigt. Diese Erscheinung lässt sich wahrscheinlich dadurch erklären, class die Einwirkung der grossen Flüsse nicht mehr so weit nach Süden reicht und das Wasser im Meere längere Zeiten unvermischt bleibt.

Bei Station 6 (F 26k) ist die Salzkonzentration im Oberflächenwasser $5.90 \%$ und auf dem Meeresboden in $40 \mathrm{~m}$ Tiefe $5.88 \%$ oder weniger als an der Oberfläche. Wie aus Abb. 2 ersichtlich, sinkt die 'Temperatur: im Oberflä.chenwasser auf $6.20^{\circ} \mathrm{C}$ oder von $6.82^{\circ} \mathrm{C}$ auf $6.20^{\circ} \mathrm{C}$. Am Meeresboden hat die Temperatur in $40 \mathrm{~m}$ Tiefe $2.90^{\circ} \mathrm{C}$ betragen und ist sogar etwas gestiegen.

Bei der Station 7 (F 30) ist die Salzkonzentration im Oberflächenwasser $5.95 \%$ und auf dem Neeresboden in $118 \mathrm{~m}$ Tiefe $6.80 \%$. Die Temjeratur cles Oberflächenwassers belief sich am $18 \mathrm{Juni}$ auf $4.66^{\circ} \mathrm{C}$ und am Meeresboden in $118 \mathrm{~m}$ Tiefe auf $2.5 \pm^{\circ} \mathrm{C}$. Diese Station liegt nördlich der Inseln Ahvenanmaa, die eigentlich verhindern, dass salzhaltiges Wasser aus der Ostsee frei in clen Bottnischen Meerbusen eindringen kamn. Diese Erscheinung geht sehr übersichtlich aus Abb. 2 hervor. Die Salzkonzentration steigt in der Ostsee cleutlich und erreicht am Meeresboden sogar 15.23\%

Bei der Station 8 (F 72a) ist die Salzkonzentration im Oberflächenwasser $6.49 \%$ und am Meeresboden in $66 \mathrm{~m}$ Tiefe $7 . \pm 3 \%$. Bei dieser Station ist der Salzgehalt schon grösser als bei den obengenannten Stationen, obwohl aus dem Fimnischen Meerbusen das Wasser mit weniger Salz in das Baltische Meer gelangt. Die Temperatul war am 19 August im Oberflächenwasser $14.73^{\circ} \mathrm{C}$ und am Meeresboden in $66 \mathrm{~m}$ Tiefe nur $2.67^{\circ} \mathrm{C}$. Wenngleich es schon cler 19 August war, war die Temperatur am Boden so gering.

Bei Station 9 (F 74 ) beträgt die Salzkonzentration im Oberflächenwasser am 19 August $7.11 \%$ und am Meeresboden in $143 \mathrm{~m}$ Tiefe $10.99 \%$. Wie aus Abb. 2 deutlich zu ersehen, steigt an dieser Stelle mit einer Eintiefung die Salzkonzentration deutlich, und da salzhaltiges Wasser schwerer als salzfreies ist, bleibt es in eine Eintiefungen der Ostsee stehen und vermischt sich nicht mit dem Oberflächenwasser. Die Temperatur betrug im Oberflächenwasser $15.35^{\circ} \mathrm{C}$ und in $143 \mathrm{~m}$ Tiefe am Meeresboclen $4.6 t^{\circ} \mathrm{C}$. 
Die Temperatur des Oberflächenwassers ist schon so hoch, dass mehrere Planktondiatomeen nicht mehr gut gedeilen können, denn sie wachsen am besten in Wasser von $5-10^{\circ} \mathrm{C}$.

Bei Station 10 (F 79) betrug die Temperatur des Oberflächenwassers am 19. August $15.64^{\circ} \mathrm{C}$ and am Meeresboden in $110 \mathrm{~m}$ Tiefe $4.73^{\circ} \mathrm{C}$ oder beinahe 11 Grad wenigex. Wie aus Abb. 2 ersichtlich, kommt im Baltischen Meere die Erscheinung überall vor, dass die Temperaturunterschiede im Sommer zwischen dem Oberflächen- und dem Bodenwasser gross sind. Die Salzkonzentration an dieser Stelle belief sich an der Oberfläche auf $6.62 \%$ und am Meeresboden in $110 \mathrm{~m}$ Tiefe auf $11.20 \%$.

Bei Station 11 (F 80) war die Salzkonzentration des Oberflächenwassers am 19. August $6.82 \%$ und in $166 \mathrm{~m}$ Tiefe am Meeresboden 12.11\% oder fast zweimal so gross wie an der Oberfläche. Die Temperatur des Oberflächenwassers betrug $15.77^{\circ} \mathrm{C}$ und in $166 \mathrm{~m}$ Tiefe am Meeresboden nux $5.20^{\circ} \mathrm{C}$.

Bei Station 12 (F 81) belief sich die Salzkonzentration des Oberflä.chenwassers am 20. August auf $7.3 \pm \%$ und in $200 \mathrm{~m}$ Tiefe am Meeresboden auf $10.43 \%$. Die Temperatur betrug in den obengenannten Tiefen 15.35 und $5.65^{\circ} \mathrm{C}$ oder der Unterschied beinahe $10^{\circ} \mathrm{C}$. Wie aus $\mathrm{Abb} .2$ deutlich hervorgeht, fällt die Salzkonzentration am Meeresboden recht beträchtlich, obwohl die Tiefe an dieser Stelle $200 \mathrm{~m}$ ausmacht, und nach den fï̈heren Erfahrungen sollte an dieser Stelle sogar mehr Salz im Wasser enthalten sein. Es ist sehr schwer zu verstehen, warum in offenen Meere ostwärts der Insel Gotland eine derartige Erscheinung zu beobachten ist. Als Erklärung lkamn nur in Frage kommen, dass süsses Wasser aus der Rigaer Bucht in die Ostsee gelangt und das Meereswasser in der Nähe der Buchtmündung versuisst.

Bei Station 13 ("10") war die Salzkonzentration im Oberflächenwasser am 20. August $7.25 \%$ und am Meeresboden in $145 \mathrm{~m}$ Tiefe $12.45 \%$. Die 'Temperatur war im Oberflächenwasser $15.53^{\circ} \mathrm{C}$ und an Meeresboden in $145 \mathrm{~m} \mathrm{Tiefe} 5.36^{\circ} \mathrm{C}$. Der Salzgehalt des Wassers ist an dieser Stelle am Meeresboden gestiegen und sogas: grösser als bei Station 11 (Abb, 2). Im Oberflächenwasser lassen sich so grosse Schwankungen nicht feststellen, clemn durch Oberflächenströmungen sowie clurch Winde wird das Wasser in clen obersten Schichten gut durchmischt.

Bei Station 14 (F 59) betrug die Salzkonzentration an der Oberfläche $7.41 \%$ und am Meeresboden $11.50 \%$. Die Temperatur im Oberflächenwasser belief sich am 20. August auf $15.6 t^{\circ} \mathrm{C}$ und am Meeresboden auf $4.31^{\circ} \mathrm{C}$.

Bei der Station 15 (»Il») war die Salzkonzentration im Oberflächenwasser am 20. August $7.16 \%$ und am Meeresboden in $95 \mathrm{~m}$ Tiefe $10.34 \%$. Die Temperatur des Oberflächenwassers belief sich auf $15.92^{\circ} \mathrm{C}$ und am Meeresboden in $95 \mathrm{~m}$ Tiefe auf nur $4.33^{\circ} \mathrm{C}$. 
Bei Station 16 ( 13 13) war die Salzkonzentration an der Oberfläche am 20. August 7.39\% und am Meeresboden in $64 \mathrm{~m}$ Tiefe $8.73 \%$ oder deutlich weniger als an der Stelle von Station 13. Aus Abb. 2 geht hervor, dass die Salzkonzentration von Station 13 südwärts im Meeresbodewasser deutlich abnimmt und ihr Minimum bei Station 16 findet. Wie wäre cliese Erscheinung zu erlklären, denn Station 16 liegt im Südencle des Baltischen Meeres, wohin salzhaltiges Wasser durch Slkagerral und Kattegatt aus der Nordsee eindringen kann.

Bei der Station 17 ("15») war die Salzkonzentration an der Oberfläche des Meeres 7.32\% und am Meeresboden in $72 \mathrm{~m}$ Tiefe $13.55 \%$. Die Wassertemperatur betrug an denselben Stellen am 21. August 15.29 und $5.04^{\circ} \mathrm{C}$. Die Salzlionzentration hat am Meeresboden deutlich zugenommen, denn diese Station liegt recht nahe der Insel Bornholm, wohin salzhaltiges Wasser gut aus der Nordsee eindringen kam.

Bei Station 18 ("16») war der Salzgehali des Oberflächenwassers am 21. August $7.3+\%$ und am Meeresboden in $83 \mathrm{~m}$ Tiefe $13.48 \%$. Aus Abb. 2 geht übersichtlich hervor, dass die beiten letzten Stationen am Meeresboden im Wasser viel meln Salz enthalten als die Stationen, die nördlich und westlich liegende. Diese Erscheinung lässt sich wahrscheinlich cladurch erlclären, class ostwärts der Insel Bornholm eine Eintiefung im Seeboden vorhanden ist, wo sich salzhaltiges Wasser angesammelt hat. Da die Insel zum Teil die Meeresströmungen lindert, ist das Wasser in dieser Eintiefung salzhaltiger als an den seichteren Stellen.

Bei Station 19 ("17)) war die Slazkonzentration im Oberflächenwasser am 23. August $7.63 \%$ und am Meeresboden in $40 \mathrm{~m}$ Tiefe nur $8.86 \%$. Auch an dieser Stelle enthält das Wasser am Boden deutlich weniger Salz als die beiden vorigen Stationen (Abb. 2). Die Temperatur des Wassers betrug an der Oberflä.che $15.76^{\circ} \mathrm{C}$ und am Meeresboden nur $5.04^{\circ} \mathrm{C}$. In den Wassertemperaturen besteht kein Unterschied zwischen clen anderen Stationen und der vorliegenden.

Bei Station 20 (»18») war die Salzkonzentration im Oberflächenwasser am 23. August $7.72 \%$ und am Meeresboden in $43 \mathrm{~m}$ Tiefe $13.69 \%$. Obwohl keine Tiefenunterschiede bestehen, kommen in den Salzkonzentrationen sehr grosse Unterschiede ror (Abb. 2). Worauf sie beruhen, ist nicht klar, demn Station 20 ist nicht weit von Station 19 entfernt. Die Temperatur des Oberflächenwassers belief sich auf $14.90^{\circ} \mathrm{C}$.

Bei Station 21 (\$19») war die Salzlonzentration an der Oberfläche des Meeres $7.65 \%$ und am Meeresboden in $45 \mathrm{~m}$ Tiefe $15.23 \%$. An dieser Stelle enthält im Untersuchungsgebiet das Wasser am Meeresboden am meisten Salz. Die Temperatur war im Oberflächenwasser $14.85^{\circ} \mathrm{C}$ und am Meeresboden in $45 \mathrm{~m}$ Tiefe $5.05^{\circ} \mathrm{C}$. 
Bei der Station 22 ("20») war die Salzkonzentration an der Oberfläche des Meeres am 23. August 7.79\% und am Meeresboden in $45 \mathrm{~m}$ Tiefe $10.48 \%$. Wie aus Abb. 2 ersichtlich, fällt die Salzkonzentration in der Umgebung dieser Station am Meeresboden sehr erheblich, zeigt aber an der Oberflä.che gar keinen Unterschied. Die Temperatur betrug an der Oberflä.che gar keinen Unterschied. Die Temperatur betrug an der Oberfläche $14.86^{\circ} \mathrm{C}$ und am Meeresboden in $45 \mathrm{~m}$ Tiefe $7.47^{\circ} \mathrm{C}$.

Bei del Station 23 ("21») war die Salzkonzentration des Oberflä.chenwassers am 23. August 7.70\% und am Meeresboden in $42 \mathrm{~m}$ Tiefe $10.30 \%$. Die Wassertemperatur betrug in denselben Tiefen 14.83 und $11.04^{\circ} \mathrm{C}$. Die Temperatur des Wassers ist am Meeresboden von Station 16 bis Station 23 langsam gestiegen. Wahrscheinlich haben die Strömungen, die von Osten und Westen anfeinander stiessen, das Oberflächenwasser mit dem Grundwasser vermischt, wodurch die Temperatur langasam gestiegen ist.

Zusammenfassend kann man sagen, dass die untersuchten Gebiote, Bottnischer Meerbusen und Baltisches Meer, Brackwassergebiete sind, in denen die Salzkonzentration zwischen 2 und $15 \%$ schwankt. Dieselbe Erscheinung bestätigen ihrerseits die Diatomeen, wie wir später sehen werden.

In den Binnengevässern sind die $\mathrm{pH}$-Werte von recht grosser Bedeutung für die Diatomeenflora, denn die Grössen schwanken gewöhnlich zwischen 3 und 9. In der Ostsee sowie im Bottnischen Meerbusen ist der: pH-Wert belanglos, denn er schwankt zwischen $7.7 \pm$ und 8.59, und das Wasser ist in allen Teilen des Untersuchungsgebietes alkalisch. Der Verfasser komnte feststellen, dass sich die zarteren Diatomeen im Wasser schneller auflösen und deshalb Chaetoceros-Arten, die im Plankton sehr individuenreich vorkommen, am Meeresboden nur zufällig vorhanden sind. In den Vertikalprofilen, die aus den Sedimenten entnommen worden sind, findet man zartere Diatomeen überhaupt nicht mehr. 


\section{Uber die Methodik der Diatomeenuntersuchungen}

Bei den Diatomeenuntersuchungen finclet man häufig nene Arten und Varietäten, wenn man die Präparate die reichlich Formen enthalten, länger untersucht. Schon im Jahre 1943 hat der Verfasser dieser Untersuchung geschrieben, dass aus jedem Dauer]präparat 400-500 Individuen zu bestimmen sind, wenn in einem Präparat über hundert verschiedene Diatomeenarten vorkommen (MöLder 1943, s. 15). Diese hohe Individuenzahl ist cleshalb nötig, weil sonst eine falshe Vorstellung vom Mengenverhältnis der Formen in den untersuchten Diatomeenassoziationen erhalten wird. Kommen aber in der Probe nur wenige Formen vor, damn gewöhnlich genügt es schon, wenn man hundert oder zweihundert Individuen bestimmt, demn gewöhnlich treten damn nur einige Arten in Massen auf und alle anderen Formen machen sehr kleine Prozentsätze aus.

Wie gross diese Fehler sein können, sehen wir aus Tab. 1. Von Probe 19 wurdendie Diatomeen so untersucht, dass zuerst von dem Präparatrand 100 Individuen bestimmt wurden, die in der ersten Kolumne der Tabelle wiedergegeben sind. Danach wurclen von demselben Präparat weitere 100 Diatomeen festgestellt und cliese Resultate sind in der zweiten Kolumne angegeben. So wurden insgesamt 500 Individuen bestimmt, und das dritte Hundert ist in cler dritten, das vierte in cler vierten und clas fünfte in der fünften Kolumne von Tabelle ]. wiedergegeben.

So kamen im ersten Hundert nur 30 Formen vor, im zweiten 44, im dritten 40, im vierten 39 und im fünften 36 Arten und Varietäten. Insgesamt enthielten alle 5 Teile clieses Präparats 76 Formen. Sicher hätte man bei weiterer Untersuchung noch einige neue Formen finden könmen, aber schon diese Ergebnisse zeigen, dass bei den systematischen Untersuchungen sehr viele Arten und Variotäten nicht gefunden werden, wenn man zuwenig von dem Präparat untersucht und nur 100 Individuen feststellt. Am wenigsten Arten und Varietäten waren am Rande des Präparates zu finden, oder nur 30 von den 76 Formen. Am meisten Arten und Varietäten enthält Kolumne 2 mit insgesamt 44 Formen. Wie aus Tab. 1 ersichtlich, gibt es 33 Arten und Varietäten, die nur in einer Kolumne angegeben sind. Dagegen gibt es nur 16 Formen, die in allen Kolummen vorkommen. Diese häufig 
Tabelle 1.

Salzwasserformen

Achnanthes danica (Flögel) Grun, .........

Achuanthes hauckiana Girm. .............

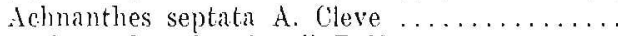

Actinocvelus ehrenbergii Ralfs ............

Actinoptychus undulatus (Bail.) Ralfs .......

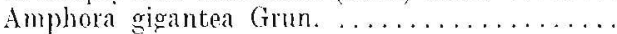

Bacterosira fragilis Gran. ..............

Cocconeis molesta Irütz. .................

Cocconeis quarmerensis Grum. . . . . . . . . .

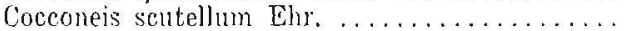

Cocconcis scutellum Ehr. var parva Grum......

Coscinodiscus kïtzingii A. Schmidt .........

Cuscinodiscus marginatus Ehr. ...........

Coscinodiscus oculus iridis Ehr. ...........

Coscinodiscus radiatus Ehr. ...............

Dimerogramma marinum (Greg.) Ralfs .......

Dimerogramma minor (Greg.) Ralfs .........

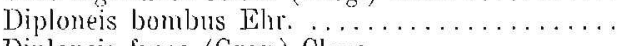

Diploneis fusca (Greo.) Cleve ..............

Dibloneis interrupta (Küt\%) Cleve ...........

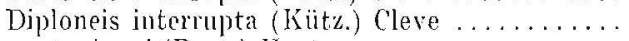
var. heeri (Pant.) Hust. . . . . . . . . . . . .

Diploneis smithii (Breb.) Cleve ...........

Fragilaria cylindrus Grum. . . . . . . . . .

Grammatophora marina (Lyngbye) Kätz......

Grammatophora ocennica (Ehr.) Ginm. ........

Grammatophora oceniea Grm. var. . ........ macilenta Grum. ...................

Hyalodisens scoticus (Kiitz.) Grom. .........

Melosira sulenta (Ehr.) Küitz. . . . . . . . . . .

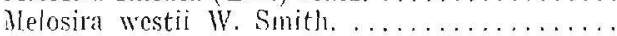

Vavicula humerosa Bréb. ................

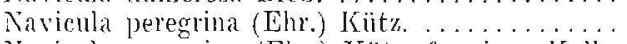

Navicula peregrina (Ehr.) Kütz. f. minor Kolbe

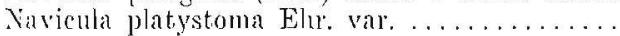
pantocsckii Wisl. et Kolb. . . . . . . . . .

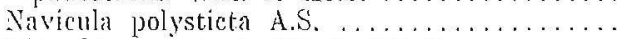

Nitzschia acminata (IV. Smith) Grun. .......

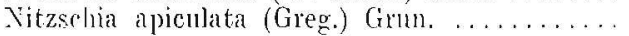

Nitzschia punctata (W. Smith) Grun. ........

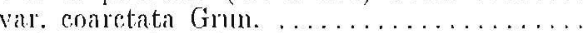

Opephora marina (Greg.) Petit. ............

Pyxidieula mediterranea Grum. ............

Rhabclonema arcuatum (Ag.) Kütz. ............

Rhoicosphenia marima (VY. Smith) M. Sehmilt

Sceletonema costatum (Grev.) Cleve .........

'thalassionema nitzschioides Grun. ..........

'T'halassiosira decipiens (Grun.) Joergensen ....

\section{Brackwasscrformen}

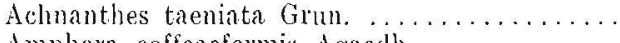

Amphora coffeneformis Agaedh ...........

Amphora commutata Grum. . . . . . . . . . . .

Bacillaria paradoxa Gmelin ..............

Caloneis permagua (Bailey) Cleve ...........

Mastogloia smithii Thwaites .............

Synedra tabulata (Agardh) Kütz. ............

l'halassiosira baltion (Grmn.) Ostenfeld

\begin{tabular}{|c|c|c|c|c|c|}
\hline 1. & 2. & 3. & 4. & 5. & $\begin{array}{l}\text { In der } \\
\text { Probe } \\
\text { zilsamm. }\end{array}$ \\
\hline$\%$ & $\%$ & $\%$ & $\%$ & $\%$ & $\%$ \\
\hline - & $\ldots$ & - & - & 1 & 0.2 \\
\hline 2 & 5 & 6 & 3 & 5 & 4.2 \\
\hline- & - & 1 & 1 & - & 0.4 \\
\hline 17 & 6 & 2 & 4 & 7 & 7.2 \\
\hline.-- & 1 & $\ldots$ & - & 1 & 0.4 \\
\hline 一 & 1 & 2 & 3 & 1 & 1.4 \\
\hline- & 2 & 1 & $\ldots$ & - & $0 . t i$ \\
\hline- & - & 1 & - & $\ldots$ & 0.2 \\
\hline- & 1 & - & - & - & 0.2 \\
\hline 4 & 5 & $\downarrow$ & 1 & 4 & 3.6 \\
\hline- & 1 & 2 & - & -- & 0.6 \\
\hline 5 & 3 & 8 & 2 & 5 & 4.6 \\
\hline- & 1 & 1 & 2 & 1 & 1.0 \\
\hline- & - & 1 & 3 & 2 & 1.2 \\
\hline 2 & 1 & 1 & 1 & - & 1.0 \\
\hline$\ldots$ & 1 & - & - & - & 0.2 \\
\hline - & - & 2 & 1 & - & 0.6 \\
\hline 1 & 1 & 3 & 2 & 3 & 2.0 \\
\hline- & - & - & - & 1 & 0.2 \\
\hline 1 & - & 2 & -- & - & 0.6 \\
\hline- & - & $\ldots$ & 一 & 一 & - \\
\hline 1 & $\ldots$ & - & $\ldots$ & - & 0.2 \\
\hline 2 & 1 & 2 & 1 & 3 & 1.8 \\
\hline - & 1 & - & 3 & - & 0.8 \\
\hline$t$ & 4 & 3 & 5 & 6 & 4.4 \\
\hline 10 & 5 & 4 & 5 & 5 & 5.8 \\
\hline 一 & - & - & 一 & - & - \\
\hline- & 2 & - & - & - & 0.1 \\
\hline 1 & 1 & 2 & 3 & - & 1.4 \\
\hline 1 & $\tilde{\jmath}$ & 1 & $t$ & 7 & 3.6 \\
\hline$\cdots$ & - & 1 & $\ldots$ & 1 & 0.4 \\
\hline 1 & 1 & - & - & - & 0.4 \\
\hline - & $\cdots$ & 1 & - & - & 0.2 \\
\hline 一 & 一 & 1 & - & 一. & 0.2 \\
\hline- & $\cdots$ & 一 & - & - & - \\
\hline 一 & 1 & $\ldots$ & 一 & - & 0.2 \\
\hline 一 & 1 & 一 & 一 & - & 0.2 \\
\hline- & - & - & 1 & - & 0.2 \\
\hline- & 一 & 一 & 1 & 一. & 0.2 \\
\hline- & $\cdots$ & $\cdots$ & $\ldots$ & $\ldots$ & - \\
\hline- & 1 & - & - & - & 0.2 \\
\hline 一 & - & 2 & - & 1 & 0.6 \\
\hline - & 2 & - & 2 & 1 & 1.0 \\
\hline 5 & 1 & 1 & 2 & 4 & 2.6 \\
\hline$\cdots$ & 1 & 1 & - & - & 0.4 \\
\hline - & 一 & 一 & 1 & - & 0.2 \\
\hline 2 & 2 & 1 & - & 1 & 1.2 \\
\hline 1 & 1 & 1 & 2 & 3 & 1.6 \\
\hline
\end{tabular}

0.4 1.0 2.6 0.6 0.2 0.2 9.8 3.0

$3 \quad 3854-62$ 
Tabelle 1. (Fortselzung)

Süsswasserformen

Achnanthes kyophila Petersen ............

Achnanthes saxonica Krasske ..............

Amphora ovalis Kütz. ....................

Amphora perpusilla Grun. .................

Cocconeis diminuta Pant. . . . . . . . . . . .

Cocconeis disculus Schum. ................

Diploneis puella (Schuman) Cleve ............

Navicula lucidula Grun. ......................

Navicula placentula (Elur) Grun. . . . . . . . .

Navicula placentula (Ehr.) Grun. .............

var. jenisseyensis (Grun.) Meister............

Navicula placentula (Ehr.) Grm. . .............

f. latiuscula (Grun.) Meister ...............

Navicula tuscula (Elri) Grun, .............

Opephora martyi Hériband ....................

Stephanodiseus astraea (Ehr.) Grun. ......... var. minutula (Kütz.) Grum. ...............

Stephanodiscus hantzschii Geun.

Süss- u. Brackwasserformen.

Achmanthes lemmermamii Hust.

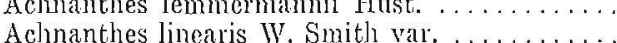

pusill Ges linearis W. Smith valr. ............

Cocconeis pediculus Ehr. .....................

Cyclotella meneghiniana Kütz. .............

Epithemia turgida (Ehr.) Kütz. ............

Fragilaria pimata Ehr. ....................

Melosira varians Agardh ..................

Rhoicosphenia curvata (Kïtz.) Grus. .........

Rhopalodia gibba (Ehr.) Müll. var. . . . . . . .

ventricosa (Ehr.) Grum.

\begin{tabular}{|c|c|c|c|c|c|}
\hline 1. & 2 & 3. & 4 & 5. & $\begin{array}{l}\text { In der } \\
\text { Proble } \\
\text { zusammm }\end{array}$ \\
\hline$\%$ & $\%$ & $\%$ & $\%$ & $\%$ & $\rho_{G}$ \\
\hline - & 1 & - & $\ldots$ & - & 0.2 \\
\hline$\ldots$ & 1 & - & - - & - & 0.2 \\
\hline 1 & 2 & - & 1 & 1 & 1.0 \\
\hline - & 4 & - & 3 & $i$ & 1.6 \\
\hline - & 1 & 3 & 2 & 2 & 1.13 \\
\hline - & $\hat{1}$ & - & $\ldots$ & $\ldots$ & 0.2 \\
\hline - & - & $\ldots$ & - & 1 & 0.2 \\
\hline - & - & 一 & 1 & - & 0.2 \\
\hline 1 & - & $\ldots$ & 1 & - & 0.4 \\
\hline - & -- & - & 一 & - & - \\
\hline - & - & 2 & - & $\ldots$ & 0.4 \\
\hline - & - & - & - & - & - \\
\hline - & - & 1 & - & - & 0.2 \\
\hline 1 & - & - & - & 1 & $0 . t$ \\
\hline$\ldots$ & $\ldots$ & - & - & 1 & 0.2 \\
\hline - & - & - & -- & - & - \\
\hline - & - & - & 1 & - & 0.2 \\
\hline - & - & - & 1 & - & 0.2 \\
\hline- & - & - & 1 & - & 0.2 \\
\hline - & -- & 一 & 一 & - & \\
\hline 一 & - & 一 & - & 1 & 0.2 \\
\hline 1 & 1 & - & 3 & 1 & 1.2 \\
\hline - & - & 1 & - & - & 0.2 \\
\hline 16 & 5 & 8 & 8 & 7 & 8.8 \\
\hline 2 & 7 & 5 & 7 & 1 & 4.4 \\
\hline 1 & - & $\ldots$ & - & $\ldots$ & 0.2 \\
\hline \pm & - & $\ldots$ & - & - & $0 . s$ \\
\hline - & - & - & - & - & - \\
\hline - & - & 1 & $\ldots$ & $\ldots$ & 0.2 \\
\hline
\end{tabular}

vorhandenen Arten sind folgende: Salzwasserformen; Achnanthes hauckiana, Actinocyclus ehrenbergii, Cocconeis scutellum, Coscinodiscus kiutzingii, Diploneis bombus, D. smithii, Grammatophora marina, G. oceanica, Melosira sulcata, Rhabdonema arcuatum, Thalassiosira decipiens. Brackwasserformen; Ampthora commutata, Synedra tabulata, Thallassiosira baltica. Süss- und Brackwasserformen; Epithemia turgida, Fragilaria pinnata. Von den Süsswasserformen kam in jeder Kolumne keine Art vor. Alle diese Diatomeen, die in allen Kolumnen vertreten sind, erreichen auch deutlich grössere Prozentsätze. So kommt Actinocychus ehrenbergii in der ersten Kolumne auf $17 \%$ und in der Probe zusammen auf $7.2 \%$ vor. Synedra tabulata wiederum erreicht in Kolumne $312 \%$, in Kolumne $513 \%$ und in der Probe zusammen sogar $9.8 \%$. Beinahe ähnliche Verhältnisse bestehen bei Epithemia turgida, die in der Probe zusammen $8.8 \%$ ausmacht und in Kolumne 1 allein $16 \%$ bildet. Aus Tabelle 1 geht cleutlich hervor, dass man bei clen systematischen Untersuchungen mehr Individuen aus dem Präparat untersuchen soll, wenn man genauere Ergebnisse erzielen will. Ebenso schwankt 
Tabelle 2.

\begin{tabular}{|c|c|c|c|c|c|c|}
\hline Okologisehe Gruppen & 1. & 2. & 3. & 4. & 5. & Zusammen \\
\hline Salzwasserformen & $60 \%$ & $59 \%$ & $58 \%$ & $53 \%$ & $63 \%$ & $58.6 \%$ \\
\hline Brackwasserforme $\ldots \ldots \ldots \ldots \ldots \ldots \ldots \ldots \ldots$ & $13 \%$ & $18 \%$ & $21 \%$ & $17 \%$ & $20 \%$ & $17.8 \%$ \\
\hline Sïss- und Brackwasserformen. & $24 \%$ & $13 \%$ & $15 \%$ & $19 \%$ & $10 \%$ & $16.2 \%$ \\
\hline Sïsswasserformen $\ldots \ldots \ldots$. & $3 \%$ & $10 \%$ & $6 \%$ & $11 \%$ & $7 \%$ & $7.4 \%$ \\
\hline
\end{tabular}

die Artenzahl recht stark, wie z. B. von 30 bis 76 , was schon zeigt, welche grossen Fehler vorkommen können. So sind in Kolumme 5 sogar 6 nene Arten angegeben, die im Präparat früher nicht festgestellt worden sind. In Kolumne 1 finclen sich sogar 4 Formen, die man später nicht mehr angetrofen hat. Besser ist der Sachverhalt auch in den Kolummen 2 -4 nicht, wo insgesamt 23 Arten vertreten sind, die nur in einer Kolumne erscheinen. Hätte man nur 100 Individuen bestimmt, so wären diese 23 Formen ausgelieben und die Probe systematisch ungenügend untersucht worden.

In Tabelle I sind die Diatomeen in ökologische Gruppen so eingeteilt, class alle Salzwasserdiatomeen ihre eigene Gruppe bilden, desgleichen auch die Brackwasserformen, die Süss- und Brackwasserformen und schliesslich die Süsswasserdiatomeen. Bei näherer Betrachtung der Süsswassergruppe ist zu exkennen, dass alle Formen sehr selten vorlzommen. Etwas häufigen' sind unter ihmen Amphora ovalis, A, perpusilla und Cocconeis diminuta, die aber auch nicht grössere Individuenzahlen erreichen.

Tab. 2 stellt ein ölrologisches Spektrun von Tab. 1 dar, in dem die ölkologischen Gruppen in Prozent wiedergegeben sind. Aus dieser Tabelle geht hervor, dass die zu den verschiedenen ölkologischen Gruppen gehörenden Diatomeen in den einzelnen Kolumnen prozentual häufig ganz ungleichartig vertreten sind. In Kolumme 4 ist der Prozentsatz der Salzwasserdiatomeen nux 53 und in Kolumne 5 wiederum 63.

Alle andere Prozentsätze der Salzwasserformen liegen zwischen 53 und 63, und alle Individuen der Probe machen zusammen 58.6\% aus. Jetzt erhebt sich die Frage, warum diese Unterschiede zwischen den Prozentsätzen bestehen. Wie aus Tab. I hervorgeht, kommen diese Schwankungen dadurch zustande, dass in der ersten Kolumne Actinocyclus ehrenbergii $17 \%$, Grammatophora oceanica $10 \%$ und Rhabdonema arcuatum $5 \%$ ausmachen. In den anderen Kolumnen haben diese Diatomeen wiederum viel geringere Prozentsätze. Aus dieser Erscheinung sieht man, dass einige Diatomeen bei cler Herstellung der Präparate mehr in deren Ränder gehen und andere Formen in der Mitte bleiben. 
Grosse Schwankungen sieht man auch bei den Brackwasserformen, wo sie zwischen 13 und $21 \%$ ausmachen. In der ganzen Probe zusammen liegt der Prozentsatz bei 17.s oder beinahe in der Mitte zwishen den Grenzwerten. Auch unter den Brackwasserdiatomeen kommt Symedra tabulata in den einzelnen Kolumnen sehr schwankend vor. In der Süss- und Brackwassergruppe schwanken die Zahlen sogar zwischen 10 und 24 , und der Mittelwert für dieses Präparat ist wiederum 16.2\%. Diese grossen Schwankungen sind von Epithemia turgida und Fragilaria pinnala abhängig, von denen erstere am Rande und letztere in der Mitte des Präparates reichlicl vorkommt. Obwohl Süsswasserdiatomeen sehr spärlich vorkommen, schwanken die Prozentsätze in den Kolummen zwischen 3 und 11. Dieses Schwanken ist davon abhängig, class in den Kolumnen viele Arten nur ein einziges Mal vorkommen. Solche Formen sind z. B. Achnanthes kryophita, A. saxonica, Cocconeis disculus, Diploneis puella, Navicula lucidula, N. placentula var. jenisseyensis und var. latiuscula, Opephora martyi, Stephanodiscus astraea var. minumla und S. hantzschii oder 10 Arten und Varietäten.

Jetzt erhebt sich die Frage, wie diese Schwankungen bei den quartärgeologischen Untersuchungen wirken. Es ist sicher, dass cliese Schwankungen dann recht klein sind, wenn in der Probe wenige Arten und Varietäten vorkommen. Wenn die Arten- und Varietätenzahl aber gross ist, steigen die Fehler deutlich. Wie aus Tab. 2 zu ersehen, weichen die Prozentsätze deutlich voneinander ab. Deshalb kann man leicht eine falsche Vorstellung von der Salzkonzentration des Wassers erhalten. Nach meiner Ansicht haben die Quartärgeologen durch mangelhafte Diatomeenkenntnis und durch fehlerhafte Untersuchungsmethode die Vorstellung gewommen, dass das Litorinameer mehr. Salz enthalten habe als die Ostsee jetzt und auch während der Postlitorinazeit. Es ist irreführend, wenn man von den Proben in den Vertikalprofilen nur grössere Formen bestimmt und alle kleineren Diatomeen weglässt. G'erade unter den kleineren Diatomeen finden sich zum grössten Teil Süsswasserformen. 


\section{Planktondiatomeen des Untersuchungsgebietes}

\section{BOTTNISCHER MEERBUSEN}

Dem Bottnischen Meerbusen wurden im Sommer 1958 als das Motorschiff "ARANDA" seine Reise in dieses Gebiet unternahm (Abl. 3), insgesamt 18 Planktondiatomeenproben entnommen. Wahrscheinlich findet man im Plankton deshalb recht wenig Arten und Varietäten, weil cliese Reise und das Sammeln der Proben im Monat Juni, als das Wasser im Meerbusen nocl recht Kalt war, vor sich gingen.

Probe 1 ( $\mathrm{F} 2$ ) enthielt folgende Formen: Melosira granulata (Ehrl) Ralfs - $1 \%$, M. juergensii Agardh - $5 \%$, Thalassiosira baltica (Grun.) Ostenfeld - $15 \%$, Stephanodiscus hantzschii Grun. - 1\%, Chaetoceros holsaticus Schütt - $1 \%$, Tabellaria fenestrata (Lyngbye) Kütz. - $1 \%$, Diatoma elongatum (Lyngbye) Agardl - $3 \%$, Synedra tabulata (Agardh) Kütz. - $1 \%$, Achnanthes linearis (W. Smith) Grun. - 42\%, and A. taeniata Grum. $30 \%$ oder insgesamt nur 10 Arten.

Probe 2 ( F 12) enthielt folgende Formen: Melosira juergensii - 2.5\%, Thalassiosira baltica - 3.5\%, Diatoma elongatum - 3\%, Fragilaria cylindmus Grun. - $1 \%$, Achnanthes linearis-23.5\%, A. taenita- $60 \%$, Navicula gastrum Ehr. - 1\%, N. lundströmi Cleve-0.5\%, Nitzschia capitellata Hust. $-0.5 \%, N$. subcapitellata Hust. - $0.5 \%$ and Surivella ovata Kütz. - $0.5 \%$ odex in dieser Probe insgesamt 11 Arten.

Probe 3 (F 13) enthält folgende Formen: Thalassiosira baltica - $5 \%$, Chaetoceros holsaticus - $1 \%$, Ch. muelleri Lemmermann - $1 \%$, Achnanthes coarctata (Bréb.) Grun. - $1 \%$, A. linearis - $31 \%$ und A. laenita - $53 \%$ oder insgesamt nur 8 Arten.

Probe 4 (F 17) enthielt folgende Formen: Thalassiosina baltica - 8\%, Cyclotella meneghiniana Kütz. - $1 \%$, Stephanodiscus hantzschii- $2 \%$, Actinocyclus ehrenbergii Rals - $1 \%$, Chaetoceros wighamii - $21 \%$, Tabellaria flocculosa (Roth) Kütz. - 1\%, Fragilaria cylindrus - $1 \%$, Synedia tabulata - $1 \%$, Asterionella formosa - $1 \%$, Achnanthes linearis - $10 \%, A$. taeniata - $51 \%$, Rhoicosphenia curvata (Kütz.) Grun. - $1 \%$ und $N$ avicula r.ynchocephala. Küitz. - $1 \%$ oder insgesamt 13 Arten. In dieser Probe kan 


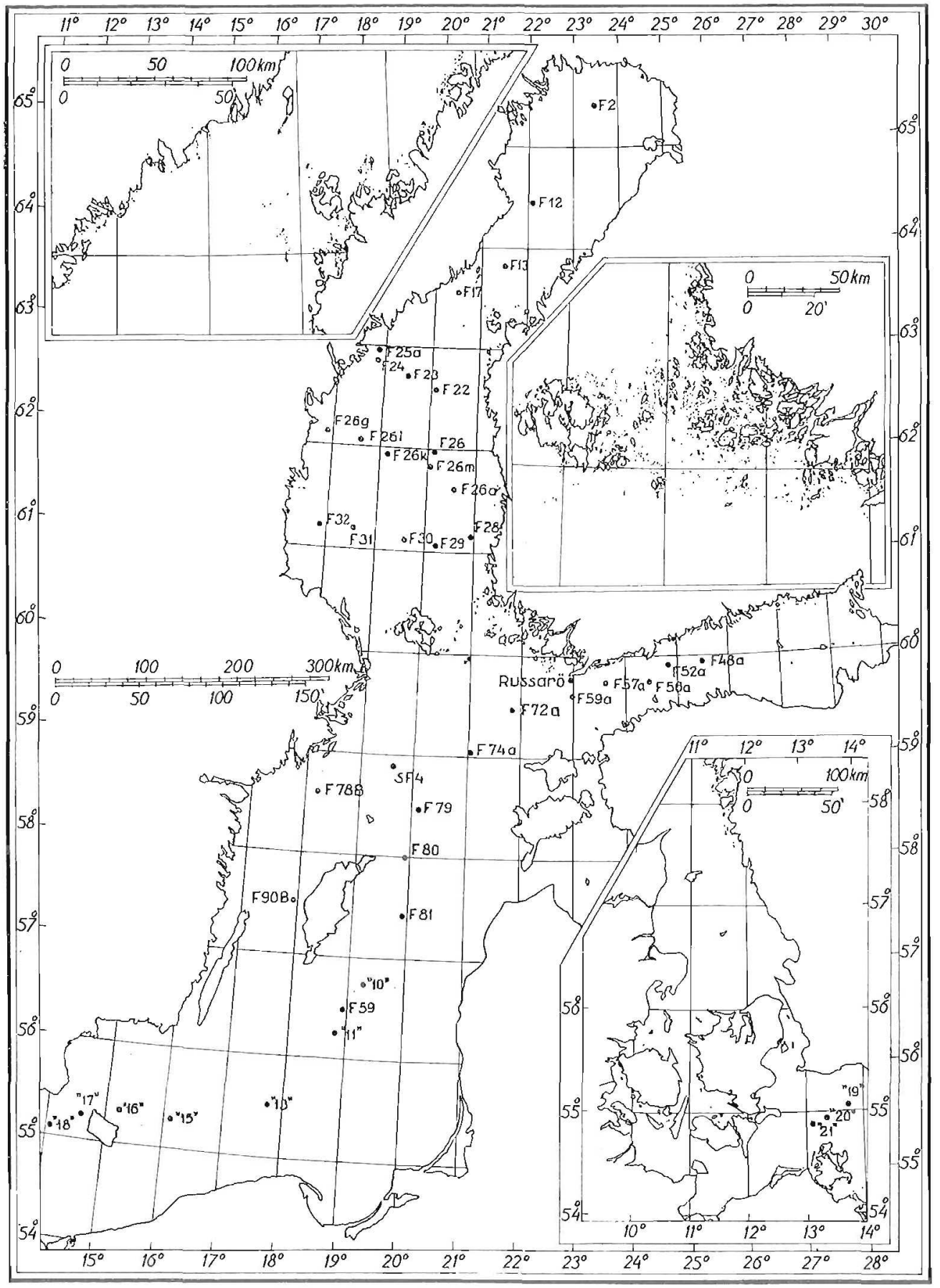

Abbildung 3. Probentmahmestellen der Diatomeen in der Ostsee. 
zum erstenmal Actinocychus ehrenbergii vor, der im Baltischen Meere gut gedeihen kann.

Probe 5 (F 22). Thalassiosira baltica - 36\%, Actinocyclus ehrenbergii $-3 \%$, Chaetoceros holsaticus - $36 \%$, Ch. wighamii- $19 \%$, Tabellaria fenestrata - $2 \%$, Diatoma elongatum - 3\% und Achnanthes taeniata - $1 \%$ oder insgesamt nur 7 Arten.

Probe 6 (F 23). Thalassiosira ballica - $21 \%$, Coscinodiscus radiatus Ehr. - $1 \%$, Chaeloceros boreatis Bailey - 3\%, Ch. holsaticus - $60 \%, \mathrm{Ch}$. wighamii - $11 \%$, Diatoma elongatum - $3 \%$ und Synedra tabulata - $1 \%$ oder insgesamt 7 Arten, wie in der voriger Probe.

Probe 7 (F 25 a). Thalassiosira baltica $-14 \%$, Chaeloceros gracilis Schüt - $11 \%, C 7$. muellerii - 3\%, Ch. wighamii - 55\%, Diatoma elongatum- $11 \%$ und Achnanthes taeniata - $5 \%$ oder wieder 7 Arten.

Probe 8 (F 26). Thalassiosira baltica - $29 \%, T$. decipiens (Grun.) Jörgensen - $1 \%$, Chactoceros boreatis - $1 \%$, Ch. gracilis - 4\%, Ch. muelleri $-1 \%$, Ch. wighamii- $47 \%$, Eunotia pectinalis (Kütz.) Rabenh. var. ventralis (Ehr.) Hust. - $1 \%$, Achnanthes linearis - $2 \%$ und A. taeniala $-1+\%$.

Probe 9 (F 26 a). Thalassiosira baltica- $71 \%$, Stephanodiscus hantzschii - $1 \%$, Chatoceros borealis - $4 \%$, Fragilaria cylindrus - $1 \%$, Synedra tabulata - $1 \%$, Achnanthes linearis - $1 \%$, A. taeniata - $20 \%$ und Nilaschia frustulum (Kütz.) Grun. var. subsalina Hust. - $1 \%$.

Probe 10 (F $26 \mathrm{k}$ ). Thatassiosira baltica-74\%, Actinocyclus elwenbergii - $6 \%$, Chaetoceros borealis - 5\%, Ch. holsaticus - $13 \%$ und $C h$. wighamii-2\% oder nur 5 Arten.

Probe 11 (F 26 i). Thalassiosira baltica-37\%, Chaetoceros borealis $-1 \%, C h$. gracitis - $7 \%$, Ch. wighamii - $53 \%$ und Achnanthes taeniata - $2 \%$ oder wieder nur 5 Arten.

Probe 12 (F $26 \mathrm{~g}$ ). Thalassiosira ballica - $5 \%$, Chaetoceros gracilis $21 \%$ : Ch. muellerii - 8\%, Ch. wighamii-56\%, Fragilaria crolonensis Kitton - 8\%, Synedra acus Kütz. var. angustissima Grun. - $1 \%$ und Asterionella formosa - $1 \%$.

Probe 13 (F $26 \mathrm{~m}$ ). Thalassiosira baltica - 91\%, Chaetoceros gracitis - $3 \%$, Ch. wighamii - 5\% und Achnanthes taeniata - $1 \%$.

Probe 14 (F 28). Thalassiosira baltica - $23 \%$, Chaetoceros borealis $5 \%$ \% Ch. holsaticus - $22 \%$ und Ch. wighamii - $50 \%$ oder nur 4 Arten.

Probe 15 (F 29). Thalassiosira baltica-63\%, Actinocyclus ehrenbergii $-4 \%$, Chactoceros borealis $-5 \%$, Ch. wighamii - $24 \%$ und Achnanthes taeniata-4\%.

Probe 16 (F 30). Thalassiosira ballica - 54\%, Actinocyclus ehrenbergi $-6 \%$, Chatoceros borealis - $8 \%$, Ch. holsaticus - $24 \%$ und Ch. wighamii $-8 \%$. 
Probe 17 (F 31). Thalassiosira baltica - $19 \%$, Chaetoceros borealis $5 \%$, Ch. holsaticus - $42 \%$, Ch. wighamii-- $22 \%$ und Achnanthes taeniata. $-12 \%$.

Probe 18 (F 32). Thalassiosira baltica - 6\%, Chactoceros holsaticus $48 \%$, Ch. muellerii-. $6 \%$ und Ch. wighamii-40\%.

Wie aus dem Obigen zu ersehen, krommen die Brackwasserdiatomeen in allen Proben vor und erreichen ihre maximale Entwicklung in den Proben $9,10,13,15$ und 16 . Alle diese Proben stammen aus der Mitte des Bottmischen Meerbusens und zeigen, dass diese Diatomeen weit vom Meeresufer entfernt gut gedeihen können. Beinahe in allen Proben zeigen sich auch Chaetoceros-Arten und erreichen sogar grosse Individuenzahlen. Es ist schade, dass diese Diatomeen so vergänglich sind, dass sie sich in den älteren Meeressedimenten nicht erhalten haben. Obwohl insgesamt 18 Planktonproben aus dem Bottnischen Meerbusen untersucht worden sind, haben sie zusammen nur 30 Arten und Varietäten enthalten. Das lässt sich wahrscheinlich daclurch erklären, dass alle diese Proben Anfang Juni gesammelt worden sind, als das Wasser noch sehr kalt war und in den nördlichen Teilen sogar Eisschollen trieben. Da das Wasser auch recht süss war, kamen. nur einige Salzwasserdiatomeen in einigen Proben zufällig vor. Anderseits fehlen in den südlicheren Teilen auch Süsswasserdiatomeen im Plankton völlig, wenngleich viele grosse Flüsse ihr Wasser in den Bottnischen Meerbusen ergiessen.

\section{FINNISCHER MEERBUSEN}

Aus dem Finnischen Meerbusen sind nur westlich der Stadt Helsinki Diatomeenproben gesammelt worden. Daher lässt sich keine Vorstellung von den Planktondiatomeen des Fimischen Meerbusens östlich der Stadt Helsinki gewinnen.

Probe 19 (F 48a). Thalassiosira baltica - 31\%, Actinocyclus ehrenbergii - $10 \%$, Chaetoceros borealis - $4 \%$, Ch. gracilis - 46\%, Tabellaria jenestrata-1\%, T. flocculosa-1\%, Licmophora paradora (Lyngbye) Agardh - $1 \%$, Synedra tabulata - $5 \%$ und Gomphonema constriclum Ehr. $-1 \%$ oder nur 9 Arten auch in einer Probe aus dem Finnischen Meerbusen.

Probe 20 (F 52a). Thalassiosiva baltica - 35\%, Actinocyclus elwenberyit $-25 \%$, A. ehrenbergii var. ralfsii (Smith) Hust. - $1 \%$, Chaetoceros gracilis - $30 \%$, Ch. wighamii - 5\%, Tabellaria jenestrata - $1 \%$, Stephanodiscus astraea (Ehr.) Grun. var. minutula (Kütz.) Grun. - $1 \%$, Achnanthes taeniata - $1 \%$ und Stauroneis anceps Ehr. var. hyalina Brun et Peragallo - ] \%, oder wieder 9 Arten und Varietäten. 
Probe 21 (F 56a). Melosira sulcata (Ehr.) Kütz. - $1 \%$, Thalassiosira baltica - $36 \%$, Actinocyclus elwenbergii $28 \%$, Chactoceros borealis - $1 \%$, Ch. gracilis - $18 \%$, Ch. wighamii - $3 \%$, Tabellaria jenestrata - $3 \%$, Synedra pulchella (Ra.fs) Kütz. - $1 \%, S$. tabulata - $7 \%$, Navicula placentula (Ehr.) Grun. - $1 \%$ und N. radiosa Kütz. - $1 \%$.

Probe 22 (F 57a). Thalassiosira baltica - $22 \%$, Coscinodiscus radiatus $-1 \%$, Actinocychus ehrenbergii - $40 \%$, A. ehrenbergii var. crassa. (W. Sm.) Hust. - $3 \%$, Chaetoceros danicus Cleve - $9 \%$, Ch. gracilis - 6\%, Ch. holsaticus - 1\%, Ch. wighamii - $17 \%$ und Synedia tabulata - $1 \%$.

Probe 23. Diese Planktonprobe wurde nicht weit von der Insel Russarö entnommen und enthielt folgende Diatomeen: Thalassiosira baltica - $64 \%$, Tabellaria flocculosa $-2 \%$, Thalassionema nilzschioides - $1 \%$, Diatoma elongatum - $28 \%$, Synedra tabulata - $1 \%$ und Achnanthes taeniata - $4 \%$. In dieser Probe kommt Diatoma elongatum recht häufig vor, und diese Erscheinung ist durch Ufernähe zu erklären.

Probe 24 (F 59). Actinocyclus ehrenbergii - $13 \%$, Chaetoceros borealis $3 \%$, Ch. danicus - $12 \%, C h$. gracitis $-47 \%$, Ch. muellerii $-10 \%, C h$. wighamii - $8 \%$, Tabellaria fenestrata - $2 \%$ und $T$. flocculosa $-5 \%$.

Probe 25 (F 59a). Melosira dislans (Ehr.) Kütz. - $1 \%$, M. juergensii $-1 \%$, Stephanodiscus astraea var. minutula - $2 \%$, Thatassiosira baltica - $14 \%$, Actinocyclus ehrenbergii - $20 \%$, A. ehrenbergii var. crassa - $5 \%$, Chaeloceros gracilis - $43 \%$, Ch. wighamii - $12 \%$, Asterionella formosa $1 \%$ und Navicula radiosa - $1 \%$.

Auch in den Planktonproben aus dem Finnischen Meerbusen konnten insgesamt 30 Arten und Varietäten festgestellt werden. Obgleich insgesamt nur 30 Formen beobachtet worden sind, finden sich unter ihnen sogar 1J, die im Bottnischen Meerbusen nicht angetroffen worden sind. Dieser Unterschied ist davon abhängig, dass das Wasser aus der Ostsee viel leichter in den Finnischen Meerbusen eindlingen kann und dabei auch die Diatomeen mitbringt.

\section{OSTSTEGEBIET}

Probe 26 (F 72a). Diese Planktonprobe wurde am 19. August 1958 gesammelt und enthielt folgende Formen: Thalassiosira baltica $-23 \%$, Actinocyclus chrenbergii - $71 \%$, Chactoceros holsaticus - 4\%, Tabellaria fenestrata - $1 \%$ und Licmophora paradoxa - $1 \%$ oder nur 5 Arten. In dieser Probe kommt Actinocychus ehrenbergi schon sehr individuenreich vor und macht sogar $71 \%$ von allen in der Probe gesehenen Formen aus.

Probe 27 (F 74a). Thalassiosira baltica - 4\%, Coscinodiscus kiuzingii A. Schmidt - 1\%, Actinocyclus ehrenbergii - $70 \%$. A. ehrenbergii var. crassa - $1 \%$, Chaetoceros borealis $-8 \%$, Ch. holsaticus $-6 \%$ und $C h$. wighamii - $10 \%$.

$4 \quad 3851-62$ 
Probe 28 (F 4). Thalassiosira baltica - $24 \%$, Actinocyclus ehrenbergii $-2 \%$, Chaetoceros gracilis - $32 \%$, Ch. muellerii- $10 \%, C h$. wighamii - $31 \%$ und Tabellaria fenestrata - $1 \%$.

Probe 29 (F 78B). Thalassiosira baltica - $14 \%$, Actinocyclus ehrenbergit $-4 \%$, A. ehrenbergii var. crassa - 8\%, Chaetoceros boreatis - $17 \%$, Ch. gracilis - $33 \%$, Ch. wighamii - $16 \%$ und Synedra tabulata-8\%. Auch diese Probe enthält sehr wenig Arten.

Probe 30 (F 79). Thalassiosiva baltica - $11 \%$, Actinocychus ehrenbergii $-42 \%$, A. ehrenbergii var, ralfsii - $3 \%$, Chactoceros borealis - $33 \%$, Ch. holsaticus - $3 \%$, Ch. wighamii - $4 \%$, Licmophora paradoxa - $1 \%$, Synedra tabulala - $1 \%$, S. tabulata var. fasciculala (Kütz.) Grun. - $1 \%$ und Diploneis puella (Schumann) Cleve $-1 \%$.

Probe 31. (F 80). Thalassiosira baltica - $7 \%$, Actinocyclus ehrenbergii - $59 \%$, Chactoceros borealis - $24 \%$ und Ch. holsaticus - $10 \%$ oder nur 4 Arten.

Probe 32 (F 90B). Thalassiosira baltica-4\%, T. decipiens $-1 \%$, Slephanodiscus hantzschii - $1 \%$, Actinocyclus ehrenbergii - $46 \%$, Chactoceros boreatis $-7 \%$, Ch. gracilis $-32 \%$, Ch. muellerii- $5 \%$ und $C h$. wighamii - $4 \%$.

Probe 33 (F 81). Thalassiosina ballica - $32 \%$, Actinocyclus ehrenbergii - $45 \%$ und Chatoceros borealis - $23 \%$ oder nur 3 Arten.

Probe 34 ("10»). Thalassiosira baltica - $2 \%$, Coscinodiscus rothii (Ehr.) Grun. var. subsalsa (Juhl.-Dannf.) Hust. - . $\%$, Actinocyche elwenbergii $20 \%$ und Chactoceros borealis - $77 \%$.

Probe 35 (F 59). Thalassiosiva ballica - 1\%, Actinocyclus ehrenbergii $-5 \%$, Chaetoceros borealis - $5 \%$, Ch. gracilis - $61 \%$, Ch. muellerii $22 \%$ und $C h$. wighamii - $5 \%$.

Probe 36 (»11)). Thalassiosira baltica - $10 \%$, Actinocychus ehrenbergii $21 \%$, Chaetoceros borealis - $36 \%$, Ch. gracilis - $29 \%$, Synedra tabulata - $1 \%$, Cocconeis scutellum Ehr. - $1 \%$, Achnanthes hauchiana Grun. $1 \%$ und Amphora commutata Grun. $-1 \%$.

Probe 37 ("13»). Thalassiosira baltica-1\%, Actinocyclus ehrenbergii - $19 \%$, A. ehrenbergii var. crassa - $1 \%$, Chactoceros borealis - $29 \%$, Ch. gracilis - $47 \%$, Synedra tabulata-2\% und Amphora commutata - $1 \%$.

Probe 38 ("15»). Thalassiosira baltica - $2 \%$, T. decipiens - 1\%, Actinocyclus elwenbergii $-24 \%$, A. ehrenbergii var. ralfsii - $3 \%$, Chactoceros borealis - $62 \%$, Ch. gracilis $-7 \%$ und $C h$. wighamii $-1 \%$.

Probe 39 ("16"). Thalassiosira baltica - 4\%, Stephanodiscus hantzschii $-3 \%$, Cyclotella stelligera Cleve et Grun. - $1 \%$, C. kiulzingiana Thwaites -. $4 \%$, Actinocychus chrenbergii - $35 \%$, Chaetoceros borealis - $52 \%$ und Diploneis ovalis (Hilse) Cleve var. oblongella (Näg.) Cleve $-1 \%$. 
Probe 40, Christjansö, nicht weit rom Ufer. Actinocyclus ehrenbergii - $14 \%$, Chaetoceros borealis - $84 \%$ und Ch. holsaticus - 2\%. Wie man sieht, hat die kleine Insel keine Einvirliung auf das Plankton.

Probe 41 ("17》). Skeletonema costatum (Grev.) Cleve - 2\%, Actinocyclus ehrenbergii - 59\%, Chactoceros borealis - 20\%, Ch. muellerii - $16 \%$ und Achranthes taeniata $-3 \%$.

Probe 42 (1)18)). Thalassiosiva decipiens - $1 \%$, Actinocychus ehrenbergii $-7 \%$, A. ehrenbergit var. ralfsii - $1 \%$, Chueloceros boreatis $-87 \%$ und Ch. muellerii $-4 \%$.

Probe 43 ("19"). Thalassiosiva decipiens - $3 \%$, Actinocyclus chrenbergii - $40 \%$, A. ehrenbergii var. ralfsii - 5\%, Chaetoceros borealis - 44\%, Ch. gracilis - $1 \%$ und Diploneis smithii (Bréb.) Cleve - $1 \%$.

Probe 44 ("20"). Cyclotella kiutzingiana - $3 \%$, Thalassiosira baltica $1 \%$, I. decipiens - $1 \%$, Actinocyclus ehrenbergii - $43 \%$, Chatoceros borealis - $51 \%$ und Ch. gracilis - $1 \%$.

Probe 45 (121»). Cyclotella kützingiana - $2 \%$, Thalassiosiva baltica$4 \%$. Actinocyclus ehrenbergii - $16 \%$, Chaloceros boreatis - $73 \%$, Ch. gracitis - $4 \%$ und Synedra labulata - $1 \%$.

Probe 46 (A). Gesammelt am 24. VIII. 58. Thalassiosira ballica - $1 \%$, Aclinocyclue ehrenbergii - $17 \%$, Chaetoceros borealis - $49 \%$, Ch. danicus $-24 \%$, Ch. gracilis - $5 \%$ und Ch. holsaticus - $4 \%$.

In den Planktondiatomeenproben aus der Ostsee liesen sich insgesamt 29 Arten und Varietäten feststellen, von denen 10 neu waren und im Bottnischen und Fimnischen Meerbusen nicht angetroffen worden waren. Es gibt unr einige Arten, die grössere Individuenzahlen erreichen und beinahe in allen Gegenden der Ostsee verbreitet sind. 


\section{Abhängigkeit der ökologisehen Planktondiatomeengruppen von der Salzkonzentration des Wassers}

\section{HAUPTLINIE}

In dieser Untersuchung habe ich die Diatomeen ebenso wie schon in clen im Jahre 1943 veröffentlichten Arbeiten in ökoligische Grupjen eingeteilt, denn diese Gruppen bilden zusammen das ökologische Spelztrum denjenigen Stellen, von denen sie stammen. Diese ökologischen Gruppen sind: 1. Salzwasserdiatomeen - wachsen nur in Wasser, das wenigstens $30 \% \mathrm{NaCl}$ enthält, 2. Brackwasserdiatomeen - in Wasser von 0.2 bis $30 \% \mathrm{NaCl}$, 3. Süss- und Brackwasserdiatomeen - in Süsswasser und auch in Wasser mit höchsten $8 \% \mathrm{NaCl}$ und schliesslich 4. Süsswasserdiatomeen, die nu' in Süsswasserseen, Flüssen, Bächen und Teichen gedeihen.

Diese ölkologischen Diatomeengruppen sind in Ablo, 4 graphisch wiedergegebeb. Salzwasserdiatomeen kommen in clen Proben 1 bis 7 recht spärlich vor und fehlen in Probe 1 völlig. Wie aus Abb. I ersichtlich, stammt diese Diatomeenprobe aus dem Bottnischen Meerbusen gegenüber der Stadt Kemi, wohin sich durch die grossen Süsswasserflüsse sehr viel Wasser ergiesst. Erst in den Proben 6 und 7 steigen die Prozentsätze auf 11 und 14. Diese Proben stammen aus dem Südende des Bottnischen Meerbusens, wohin das Wasser ans der Ostsee eindringen kann. Wenn wir vom Bottnischen Meerbusen nach der Ostsee lrommen, nehmen die Salzwasserdiatomeen schnell zu und erreichen bei Station $872 \%$ aller vorhandenen Diatomeen. Bei den Stationen 9-1l nehmen die Zahlen langsam zu, und in Probe 12 machen sie sogar $94 \%$ aus. Ungefähr diese Zahlen sincl auch bei den Proben 13-19 ermittelt worden, und erst in den Proben 20 und 21 kommen nur Salzwasserdiatomeen vor, während alle anderen Arten verschwunden sind. In den Proben 22 und 23 schliesen sich den Salzwasserformen einige Brackwasserdiatomeen und anch 2-3 Süsswasserformen an, die wahrscheinlich von Schweden oder von der Insel Bornholm herstammen.

Die Brackwasserdiatomeen dagegen kommen im Bottnischen Meerbusen individuenreich vor (Abb. 4). In Probe 1 machen sie $52 \%$ aus und in Probe 5 sogar $93 \%$. In den Proben 6 und 7 betragen sie 89 und $86 \%$ und 


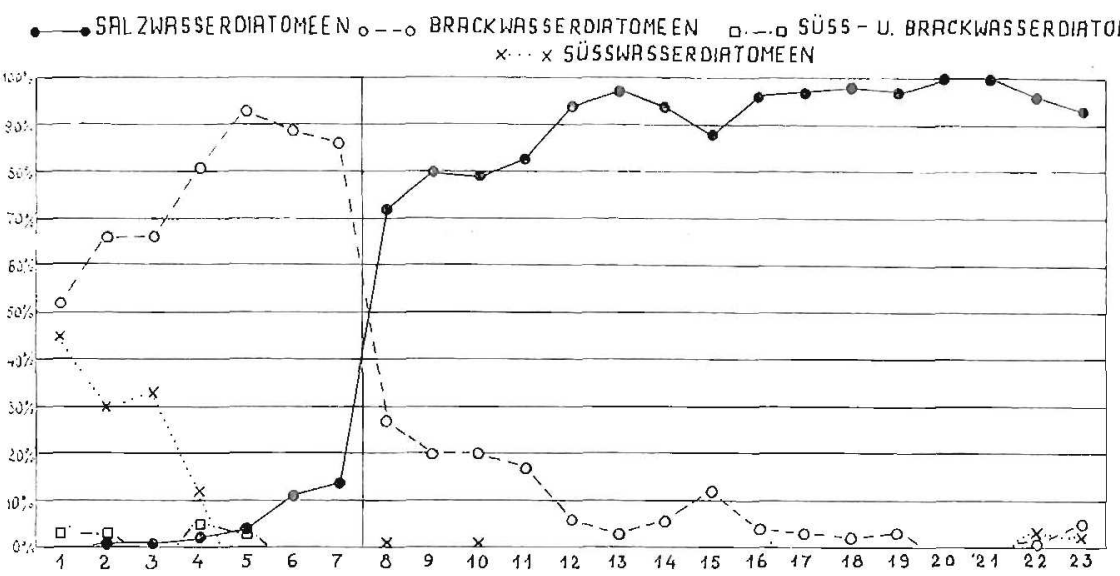

Abbildung 4.

in Probe 8 nur $27 \%$. Die letzte Probe ist schon der Ostsee entnommen, und die Salzkonzentration des Wassers hat sich an dieser Stelle auf 6.5\% belaufen. Wie aus Abb. 3 zu ersehen, nehmen die Brackwasserdiatomeen, die südlich der Probe 8 gesammelt worden sind, in den Diatomeenproben langsam ab. In den Proben 20 und 21 kommen sie überhanpt nicht mehr ror.

Wie Abb. 2 zeigt, steigt die Salzkonzentration des Wassers im Untersuchungsgebiet nícht so schnell wie die Salzwasserdiatomeen. Am Nordende des Bottnischen Meerbusens ist die Salzkonzentration im Oberfkächenwasser sowie in $15 \mathrm{~m}$ Tiefe nur $2.7 \%$ und steigt bei der Probeentuahmestelle 6 schon auf $5.9 \%$. In cler Ostsee, wo die Proben $8-23$ gesammelt worden sind, steigt die Salzkonzentration nirgends über $8 \%$.

Die Süss- und Brackwasserdiatomeen kommen sehr selten in den Proben vor, die aus dem Bottnischen Meerbusen entmommen worden sind (Abb. 4). Die Süsswasserdiatomeen spielen gar keine Rolle, denn sie kamen nur in 4 Proben ein einziges Mal vor. Diese beide Gruppen sind von den Wasserströmungen in clas Plankton des Untersuchungsgebietes gebracht worden.

Wie aus dem Obigen hervorgeht, reagieren die Salz- und Brackwassercliatomeen recht gut auf die Salzkonzentratsionsschwanlkungen. In der Ostsee kann man auch die Wirkung der Nordsee feststellen. Im Plankton finclet man selten diese Salzwasserformen, die reichlich in der Nordsee wachsen. Je weiter man von der Insel Bornholm nach Norden kommt, desto weniger findet man diese seltenen Diatomeen in den Proben. Im Plankton des Bottnischen Meerbusens kommen diese sehr selten wahrzunehmenden Salzwasserformen überhaupt nicht mehr vor. Ebenso reagieren die Süsswasserdiatomeen. Sie gelangen mit den Flussströmungen in die Ostsee, und alle 
diese Formen sterben sehr schnell ab und sinken auf den Boben. Man kamm auf dem Bodenschlamm bis in $20 \mathrm{~m}$ Tiefe Süsswasserformen finden, und von dieser Tiefe an abwärts werden sie immer seltener.

\section{QUERLINIE 1}

Diese Querlinie verläuft von der Stadt Kaskinen in Finnland nach Nordingrá in Schweden (Abb. 3). Insgesamt konnten 3 Diatomeenproben gesammelt werden, in denen zusammen 11 Arten vorkamen. In jeder Probe fanden sich nur 7 Formen, von denen Thalassiosim baltica, Chaetoceros holsaticus, Ch. wighamii sehr individuenreich vorhanden waren, desgleichen in einer Probe Diatoma elongatum. Nur in der Probe 22 lram Tabellaria fenestrata zweimal vor, so dass diese Probe eine Süsswassercliatomee enthielt. Wie aus Abb. 5 ersichtlich, treten die Salzwasserdiatomeen selnr spärlich hervor und bilden in der Probe den höchsten Prozentsatz oder $14 \%$, weil die Brackwasserdiatomeen $75 \%$ ausmachen. Wie Abb. 5 zeigt, lassen die ökologischen Diatomeengruppen nicht so grosse Schwankungen in clieser Höhe des Bottnischen Meerbusens erkennen. Unter den Algenarten sind derartige Schwankungen grösser. So macht Thalassiosira ballica in Probe $2236 \%$, in Probe $2321 \%$ und in Probe 25 a nul $14 \%$ aus. Almliche Schwankungen zeigen anch Chaetoceros-Arten. Ungelöst bleibt eigentlich die Frage, warmm in Probe 25 a die Salzwasserdiatomeen reichlicher vorkommen als in den anderen Proben, denn die Salzlonzentration des Wassers ist an dieser Stelle nicht grösser. Wahrscheinlich ist die einzige Errklärung die, dass der Wind die Oberflächenwässer von einer Stelle zur anderen treibt.

\section{QUERLTNTE 2}

Die zweite Querlinie führt von der Stadt Pori über die See nach Schweden, und auf dieser Linie wurden zusammen 5 Planktonproben gesammelt. Wie aus Abb. 6 ersichtlich, kommen Salzwassercliatomeen in der Nähe der schwedischen Küste viel reichlicher vor als in den anderen Proben. Die Salzwasserformen machen in Probe $26 \mathrm{~g} 29 \%$ aus, und in den anderen Proben schwanken die Prozentsätze zum grössten Teil unter 10\%. In clieser Probe kommt Chaetoceros gracilis sehr individuenrech vor und macht allein $21 \%$ aus.

Von den Salzwasserdiatomeen kam noch Chaetoceros muellerii vor, der nur $8 \%$ bildete. An Brackwasserformen liessen sich ebenfalls nur zwei Formen feststellen, von denen Chaetoceros wighamii allein $56 \%$ und Thalassiosira ballica nur $5 \%$ ansmachte. Der $10 \%$-ige Anteil cler Süsswasserdiato- 


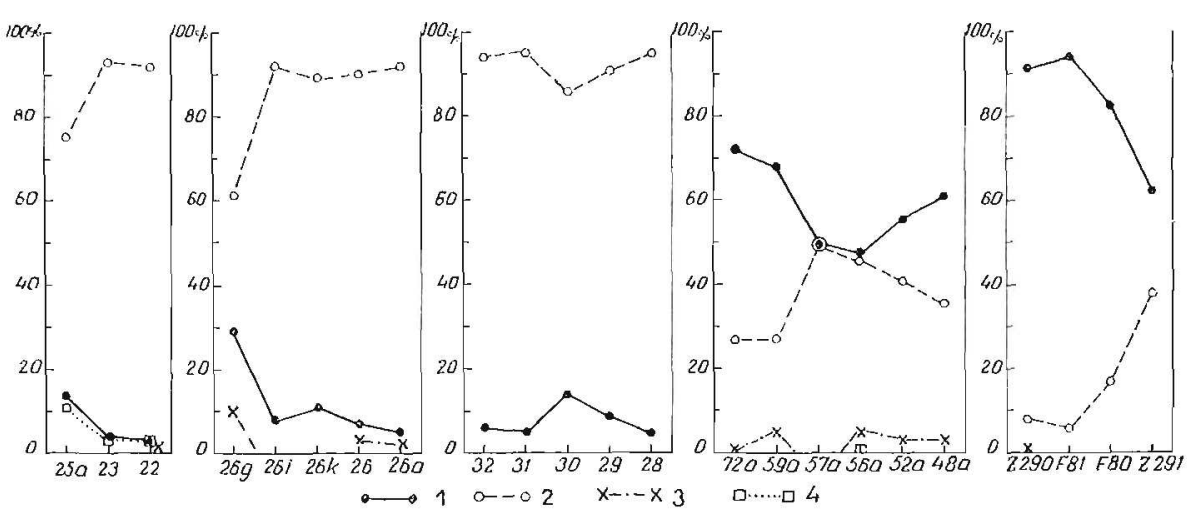

Abbildung 5, 6, 7, 8 und 9. 1. Salzwasserformen. 2. Brackwasserformen. 3. Süsswasserformen. 4. Sïss- und Brackwasserformen.

meen an dieser Probe bestätigt, dass das Meeresufer nicht weit entfernt ist und dass die Flüsse diese Formen in das Meereswasser transportieren. Dieselbe Erscheinung sieht man auch in den Proben 26 und $26 \mathrm{~A}$, wo die Süsswasserformen 3 und $2 \%$ ausmachen (Abb. 6).

In diesen Diatomeenproben, in denen die Salzwasserformen seltener vorkommen, erreicht die gewöhnliche Planktondiatomee der Ostsee, Thalassiosira baltica, sehr grosse Individuenzahlen. So macht sie in Probe 26 A 71 \%, in Probe $2629 \%$, in Probe $26 \mathrm{k} 74 \%$ und in Probe 26 i $37 \%$ aus. Derartige Prozentsätze zeigen deutlich, dass diese Planktondiatomee an einigen Stellen des Bottnischen Meerbusens besser gedeihen kann als an anderen, obwoln in den Salzkonzentrationen des Wassers die Schwankungen recht gering sind. Ähnliche Schwankungen zeigt auch Chaetoceros wighamii. So macht sie in Probe $2647 \%$ aus und in Probe $26 \mathrm{k}$ nur $2 \%$. Warum diese Formen so im Plankton vorkommen, ist dem Verfasser unklar. Wenn die Diatomeen in jeder Probe in ölsologische Gruppen eingeteilt werden, sind nicht mehr grosse Schwankungen zu sehen.

\section{QUERLINIE 3}

Diese Querlinie verläuft von der Stadt Rauma nach Westen bis nach der Küste Schwedens und insgesamt wurden 5 Proben gesammelt (Abb.7). Interessant war es, in den Proben 28 und 32 nur 4 Planktondiatomeen und in den anderen Proben nux 5 Arten festzustellen. Es ist erstaunlich, dass in diesen 5 Planktonproben zusammen nur 7 Arten vertreten waren. In Massen kamen Thalassiosira ballica, Chactoceros wighamii und Ch. holsaticus vor, und die übrigen 4 Formen komnten sehr selten gefunden werden. Abb. 
7 zeigt, dass an dieser Querlinie nux Salz- und Brackwasserdiatomeen auftreten und die beiden anderen ökologischen Gruppen fehlen. Die Prozentsätze der Salzwasserdiatomeen schwanken zwischen 5 und 14 uncl die der Brackwasserdiatomeen wiederum zwischen 86 und 95. Die Schwankungen unter den Arten sind nicht mehr so gross, wie wir es bei Querlinie 2 gesehen haben. Hier sind die Diatomeen von der Salzkonzentration des Wassers abhängig und kommen deshalb auch regelmässig in allen Teilen des südlichen Bottnischen Meerbusen vor.

\section{QUERLINIE 4}

Diese Querlinie fängt suidwärts der Stadt Helsinki an und reicht bis zur Ostsee, wo die Planktondiatomeenprobe $72 \mathrm{~A}$ entnommen worclen ist (Abb. 4). Insgesamt liegen 6 Proben vor, in denen cleutlich mehr Arten vorkamen als in clen Proben von Querlinie 3. Wie aus Abb. 8 hervorgeht, schwanken die Prozentsätze unter den Salz- und ebenso Brackwasserdiatomeen selır stark. So macht Chactoceros gracilis in Probe $48 \mathrm{~A}$ schon $46 \%$ aus und Actinocyclus ehrenbergii $10 \%$. Zu der Brackwasserdiatomeen Thalassiosira. baltica $(31 \%)$ gesellt sich Synedice labulata, die gewöhnlich im Plankton nicht vorkommt. Diese Probe sowie die anderen Proben, ausser 57 a, enthalten sehr wenig Süisswasserdiatomeen, obgleich die Salzwasserdiatomeen in den Proben über $50 \%$ aller Arten ausmachen (Abb. 8). Eine Ausnahme bildet Probe 72 a, bei der Actinocychus ehrenbergii allein $71 \%$ und Thalassiosira baltica $23 \%$ aller in dieser Probe enthaltenen Diatomeen ausmacht. Wie man sieht, hat diese Salzwasserdiatomee in solcher Umgebung die besten Wachstumsbedigungen gefunden. In den anderen Proben kommt Actinocychus ehrenbergii auch individuenreich vor, und in Probe 57 a ist seine Prozentzahl 40, aber so gute Wachstumsbedingungen hat er nicht gefunden wie in der Umgebung; wo Probe 72 a entnommen worden ist (Abb. 2 und 3),

Im ganzen wirkt Abb. 8 sehr unruhig und zeigen die ölkologischen Diatomeengruppen grosse Schwankungen. Von den Süsswasserformen erscheinen Asterionella formosa, Tabellaria lenestrata, Navicula radiosa, Stephanodiscus astraea var, minutula und Stanoneis anceps var. Hyalina, die sonst im Plankton der Ostsee fehlen.

\section{PLANKTONDIATOMEEN IN DER UMGEBUNG DER INSEL GOTLAND}

Alle Planktondiatomeenproben von Abb. 9 sind recht weit von der Insel Gotland entfernt gesammelt worden, so dass eine Einwirkung der Tnsel beinahe ausbleibt. Wahrscheinlich deshalb enthalten die Proben nur Salz- und Brackwasserdiatomeen, während Süss- und Brackwasser- sowie 
Süsswasserformen fehlen. Probe F $78 \mathrm{~B}$ ist weit nördlich der Insel und nicht weit von der schweidischen Küiste entnommen worden (Abb. 3). Salzwasserdiatomeen machen zusammen $62 \%$ und Brackwasserformen wiederum $38 \%$ aus (Abb. 9). In dieser Probe erreichte die Salzwasserform Chatoceros gracilis $33 \%$ und Actinocychus ehrenbergii nur $4 \%$ aller Diatomeen. Insgesamt waren nur 7 Formen zufinden, was bestätigt, dass die Planktondiatomeenflora sehr artenarm ist. In Probe 81, beinahe in der Mitte der Ostsee gesammelt, machen die Salzwasserformen sogar $94 \%$ aus, so dass sich Thalassiosira baltica, die zu den Brackwasserdiatomeen gehört, auf $6 \%$ belief. An Salzwasserformen kamen nur Actinocyclus ehrenbergii $(45 \%)$ und Chaeloceros borealis $(49 \%)$ vor. Anch in Probe F 80 war Actinocyclus elurenbergii individuenreich anzutreffen und stand mit $59 \%$ an erster Stelle. Von den Brackwasserformen waren Thalassiosira baltica mit $7 \%$ und Chatoceros holsaticus mit $10 \%$ vertreten. Wie Abb. 4 und 9 zeigen, reagieren die Diatomeen gut auf die Ufernàhe, und man findet mehr Brackwasserdiatomeen in diesen Proben, die in Ufernähe gesammelt worden sind.

Noch deutlicher äussert sich diese Erscheinung in der Planktonprobe, die nicht weit von der Insel Russarö entnommen worden ist. Von den Salzwasserdiatomeen kam nur ein einziges Mal Thalassiosira nitzschioides vor, und Thalassiosiva baltica machte allein sogar $64 \%$ aus. Von den Süss- und Brackwasserdiatomeen ershien Diatoma elongatum so häufig, dass sie $28 \%$ betrug sich sonst aber in den Planktonproben zufällig einstelite. An dieser Stelle lebte auch Achnanthes taeniala (4\%), die in der Pojo-Bucht sehr häufig anzutreffen war (MöLder 1943, Hatare und MöLder 1958). 


\section{Verbreitung der Planktondiatomeen im Untersuchungsgebiet}

Es gibt sehr wenig Diatomeen, die in allen Teilen des Untersuchungsgebietes verbreitet sind. Diese Tatsache lässt sich durch die Salzkonzentration des Wassers erklären. Es gibt eigentlich 3 Arten, die beinahe in allen Planktonproben vorgekominen sind (Abls. 10). Diese Arten sind: Thalassiosira baltica, Actinocyclus elvrenbergii und Chaetoceros borealis. Thalassiosira ballica tritt sehr individuenreich in den Proben 6, 7 und 12 auf, in denen die Prozentsätze zwischen 58 und 78 schwanken (Abb. 10). In den Proben 13 bis 23 lsommt sie sehr selten vor, und in clen Proben 18-21 fehlt sie völlig. Alle letztgenannten Proben sind auf der Ostsee gesammelt worden, wo die Salzkonzentration des Wassers wahrscheinlich für diese Brackwasserdiatomee zu stark ist.

Die Salzwasserdiatomee Actinocychus ehrenbergii erscheint in den Proben aus dem Bottnischen Meerbusen sehr selten, erreicht aber hohe Individuenzahlen in den Proben, die der Ostsee entnommen worden sind (Abl). 10). Optimale Wachstumsbedingungen hat sie da gefunden, wo die Salzkonzentration des Wassers über $7 \%$ steigt (Abb. 2 und 10). So macht sie in Probe 18 sogar $88 \%$ und in Probe $2086 \%$ aus.

Die dritte Diatomeen, Chaetoceros borealis, kommt im Bottnischen Meerbusen zufällig und sehr selten vor (Abb. 10). Erst in Probe 1.3 erreicht sie hohe Individuenzallen $(77 \%$ ), wobei clas Wasser über $7 \%$ Salz enthält (Abb. 2). Noch bessere Wachstumsbedingungen hat sie in den südlichen Teilen der Ostsee gefunden, wo die Prozentsätze über 80 steigen. Wemn einzelne Arten so individuenreich anzutreffen sind, findet man immer sehr wenig andere Arten, und diese Zahlen schwanken gewöhnlich zwischen. 3 und 5. Wenn die Planktonproben nicht weit von den Meeresufern entnommen worden sind, lrommen erst melnere Arten und varietäten vor. Nicht alle beobachteten Arten aber sind Planktonformen, sondern die Wellen haben sie vom Boden des Litorals oder von höheren Wasserpflanzen losgerissen und in das Plankton gebracht. Unter diesen zufälligen Formen finden sich manchmal Navicula- und Pinnularia-Arten, die alle am Meeresboden wachsen. 


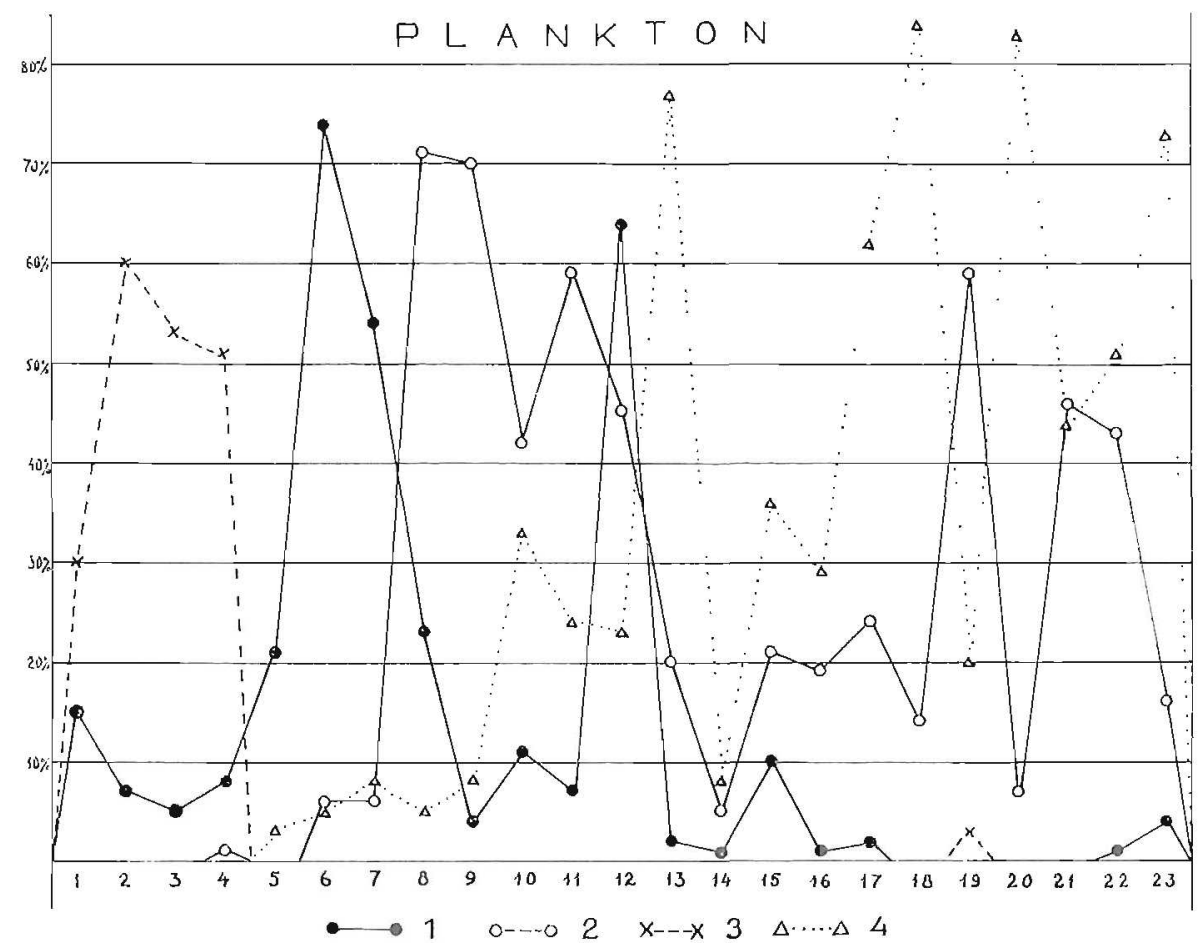

Abbildung 10. 1. 'Thalassiosira baltica. 2. Actinocyclus ehrenbergii. 3. Achnanthes taeniata. 4. Chactoceros borealis.

\section{BOTNNISCHER MEERBUSEN}

Von den Planlstondiatomeen, die beinahe nur im Bottnischen Meerbusen. vorkommen, ist Achnanthes lacniata zu nennen (Abb. 10). Höhere Indivicluenzahlen zeigt sie in den nördlichen Teilen des Bottnischen Meerbusens, wo sie in Probe 2 sogar $60 \%$ ausmacht. Nicht viel niedriger sind die Prozentsätze auch in den Proben 3 und 4. Auch Achnanthes linearis kommt beinahe nur in den nördlichen Teilen des Bottnischen Veerbusens reichlich vor. So macht sie in Probe 1 sogar $42 \%$ aus. In Probe 3 beträgt sie $31 \%$, und in den Proben 2 und 4 kommt sie schon seltener vor. Im Plankton dieser Teile des Meeres kommt sie wahrscheinlich deshalb so individuenreich vor, weil sie von den grossen Flüssen mitgebracht worden ist und beinahe in süssem Wasser weiterwachsen lrann.

In einigen Proben des Bottnischen Meerbusens krommen sehr individuenreich Chactoceros holsaticus und $\mathrm{Ch}$. wighamii vor. So macht $\mathrm{Ch}$. holsaticus in Probe 6 allein $60 \%$ und Ch. wighamii $11 \%$ aus. In Probe 9 erscheint die letztere Diatomee wiederum mit $55 \%$ und Ch. holsaticus 
überhaupt nicht. Wie man sieht, gibt es sehr wenige Arten, die weiter verbreitet sind und gute Wachstumsbedingungen gefunden haben.

Ausser den obengenannten häufig vorhandenen Diatomeen gibt es noch Formen, die eigentlich nicht zum Plankton gehören. Von diesen Formen sind zu nemmen Melosira granulata, $M$. juergensii, Diatoma elongatum, Stephanodiscus hantzschii, Tabellaria fenestrata, Fragilaria cylindrus, Asterionella formosa, Chaetoceros muellerii, Rhoicosphenia curvata, Cyclolella meneghiniana, Tabellaria flocculosa, Achnanthes coarctata und einige Arten, die zufällig in diesen aus Ufernähe stammenden Planktonproben enthalten sind. Es war eigentlich eine Überraschung, class in den Planktonproben so wenig Arten anzutreffen waren und wir es eigentlich nur mit 6-7 PJanktondiatomeen zu Tun hatten. Von den obengenannten Diatomeen sind viele typische Süsswasserformen, die im Plankton des Bottnischen Meerbusens nicht gedeihen.

\section{FINNISCHER MELRBUSEN}

Im westlichen Teil des Trimnischen Meerbusens kommen individuenreich dieselben Formen vor, die auch im Bottnischen Meerbusen häufig anzutreffen waren und grosse Individuenzahlen erreichten. Ausser diesen Diatomeen waren ferner sehr selten folgende Formen zufinden: Synedra tabulata, Licmophora paradoxa, Gomhonema constrictum, Stauroneis anceps var. hyalina, Stephanodiscus astraca var. minutula, Navicula radiosa, N. placentula und Coscinodiscus radiatus. Obgleich einige der obengenamnten Diatomeen Planktonformen sind, gehören sie im Untersuchungsgebiet nicht zu den gewöhnlichen Planlitondiatomeen und sind zufällig dorthin gelangt.

\section{OSTSEEGIEBIET}

Gewöhnliche Planktondiatomeen sind in der Ostsee Actinocyclus ehrenbergii, Chatoceros borealis, Ch. gracilis, Ch. mucllevii und Thalassiosima ballica. Alle obengenannten Salzwasserdiatomeen ausser Thalassiosira ballica. die eine Brackwasserdiatomee ist, kommen in den Planktonproben individuenreich vor. So macht Chaetoceros borealis in der Probe 13 allein $77 \%$ und Actinocyclus ehrenbergii wiederum $20 \%$ aus. Die Prozentsätze dieser. Diatomeen schwanken recht stark in den an verschiedenen Stellen der Ostsee gesammelten Proben. Dieselbe Erscheinung haben wir schon im Bottnischen Meerbusen festgestellt. Diese Schwankungen kömmen von der Salzkonzentration des Wassers ebensowenig wie von der Temperatur des Wasser's abhängig sein, denn diese beiden Faktoren schwanken im Untersuchungsgebiet eigentlich sehr wenig (Abb. 2). 
Ausser den obengenannten 5 reichlich vorkommenden Diatomeen erscheinen des weiteren zufällig und sehr selten folgende Arten: Chactoceros holsalicus, Actinocyclus ehrenbergii var. crassa, Chaetoceros wighami, Tabellaria tenestrata, Synedra tabulata, Diploneis puella, Licmophora paradoxa, Thalassiosira decipiens, Stephanodiscus hantzschii, Cocconeis scutellum, Amphora commutata, Achnanthes hankiana und noch einige im Süsswasser wachsende Diatomeen. Wie aus dem Obigen ersichtlich, kommen im Plankton der Ostsee sehr. wenige Planktondiatomeen vor, wenngleich die Salzlionzentration des Wassers von den Alandinseln bis zu der Insel Bornholm deutlich steigt (Abb. 2 und 3). 


\section{Am Meeresboden des Untersuchungsgebietes vorkommende Diatomeen}

Die Boden- oder Benthosdiatomeenproben sincl alle von der Bodenoberfläche an denselben Stellen gesammelt worden, wo die früher behandelten Planktondiatomeenproben entnommen worden sind. Während der Untersuchung dieser Proben konnte man feststellen, dass zwischen den Plankton- und Benthosdiatomeenproben ein grosser Unterschied besteht. In den Planktonproben fanden sich gewöhnnlich 3 bis 6 Arten, in den Benthosproben aber über 20 bis 40 Arten. Es ist selbstverständlich, dass unter diesen Formen viele vorkommen, die im Plankton nicht vorhanden sind.

\section{BOTTNISCHER MEERBUSEN}

Probe 1 (F 12) wurde aus $110 \mathrm{~m}$ Wassertiefe entnommen, und viele Diatomeen waren in so kleine Stïcke zerbrochen, dass es mmöglich war', diese zu bestimmen. In dieser Probe fanclen sich: Thalassiosiva baltica $35 \%$. Achnanthes tacniata - $17 \%$, Fragilaria cylindrus - 6\%, Achnanthes microcephala - 4\%, A. hanckiana - 3\%, Epithemia turgida - 3\%, Fragilaria pinnata $-3 \%$, Cyclotella ocellata $-2 \%$, Cymbella affinis - $2 \%, C$. helvetica $-2 \%$, Navicula peregrina $-2 \%, N$. tuscula f. oblusa $-2 \%$. Rhoicosphenia curvata - 2\%, Alle folgenden Diatomeen kamen nur ein einziges Mal/vor: Amphora ovalis, Caloneis amphisbaena, Cocconeis diminula. C. pediculus, Cymbella lacustris, C. prostrata, Bacillaria paradoxa, Diatoma elongatum, Fragilaria intermedia, Mastogloia smithii var. amphicephala, Melosira distans, M. sulcata, Navicula jentzschii, N. placentula, N. tomeensis Cleve, Nitzschia acuta, N. amphibia, Synedra pulchella und S. tabulata (Abb. 11). Probe 2 (F 24) Die Tiefe des Wassers betrug $80 \mathrm{~m}$. Thalassiosira ballica - $58 \%$, Achnanthes taeniata-11\%, Symedra pulchella - $7 \%$, S. Labulata $-6 \%$, Rhoicosphenia curvata - 6\%, Coscinodiscus marginatus - $2 \%$, Diatoma elongalum - 2\%, Epitemia turgida - 2\%. Alle folgenden Diatomeen machen nur $1 \%$ aus: Amphora commulata, A. ovalis, Cocconeis pediculus, Coscinodiscus lacustris, Thithemia sorex und Navicula peregrina. 
Aus derselben Probe wurde noch ein Präparat gemacht und untersucht. In diesem Präparat waren folgende Diatomeon festzustellen: Thalassiosira. batica - $47 \%$, Achnanthes taeniata - $11 \%$, Epithemia turgida - $9 \%$, Rhoicosphenia curvata - 4\%, Coscinodiscus radiatus - $3 \%$, Fragilaria cylindrus - 3\%, Synedra tabulala - 3\%, Nitzschia fonticola - $2 \%$, Tabellaria flocculosa - 2\%. Alle folgenden Diatomeen machen nur $1 \%$ aus: Achnanthes haukiana, A. microcephala, A. minutissima, Amphora commulata, Bacillaria paradoxa, Cocconeis pediculus, Coscinodiscus kützingii, C. lacustris. Cymbella aspera, Melosira islandica ssp. helvetica, Navicula hungarica, Nitaschia stagnorum, Opephora martyi, Stauroneis anceps var. hyalina und Synedra ulna. In diesem Präparat kamen viele Formen vor, die in dem ersten Präparat fehlen. In den Individuenzahlen der Diatomeen Thalassio baltica und Achnanthes taeniata waren die Unterschiede im ersteren Fall micht besonders gross, und in dem letzteren waren die Prozentesätze dieselben.

Probe 3 (F 26 a). Die Tiefe des Wassers betrug $116 \mathrm{~m}$. Präparat 1. Thalassiosira baltica - $73 \%$, Achnamhes taeniala - $6 \%$, Synedra tabalata$6 \%$. Coscinodiscus marginalus - 5\%, Epithemia largida - 5\%, Thalassionema nitzschioides - $2 \%$, Actinocyclus ehrenbergii - $1 \%$, Amphora perpusilla $-1 \%$ und Navicula crucicula - $1 \%$.

Präparat 2. Thalassiosira baltica - 53\%, Achnanthes taeniata - $11 \%$, Synedra rabulata - 5\%, Coscinodiscus radiatus - $4 \%$, Epithemia targida $-4 \%$ : Tabellaria flocculosa $-3 \%$, Actinocychus ehrenbergi - $2 \%$, Coscinortiscus kützingii - 2\%, Fragilaria cylindrus - 2\%, Synedra pulchella - 2\%: Thalassiosira decipiens - $2 \%$. Alle folgenden Diatomeen machen nur $1{ }^{\circ}{ }_{0}$ in cler Probe aus: Achnanthes minatissima, Amphora commulata, Coccone is scutellum, Coscinodiscus marginatus, Melosira distans, Navicula inflata, Rhoicosphenia curvala, Stephanodiscus hantaschii, Tabellaria fenestrala und Thalassionema nitzschioides.

\section{FINNISCHER MEERBUSEN}

Probe 4. (F 52 a). Diese Probe wurde ca. $12 \mathrm{~km}$ südlich der Stadt Helsinki aus $57 \mathrm{~m}$ Wassertiefe gehoben und enthielt folgende Diatomeen: Achnanthes taeniata - $45.5 \%$, Sceletonema costatum - $14.5 \%$, Thalassiosira decipiens - $12.5 \%$, Thalassiosiva baltica - 8.5\%, Synedra tabulata - $2.5 \%$, Coscinodiscus liützingi - $2.5 \%$, Pyxidicala mediteraneae - $3.5 \%$, Fragilavia cylindrus - $1.25 \%$, Coscinodiscus radiatus - $1 \%$, Diatoma elongatum - $1 \%$. Actinocychus ehrenbergii- $0.75 \%$, Chaetoceros muelleri- $0.75 \%$, Coscinodiscus marginatus - $0.75 \%$, Nitzschic acuta - 0.5\%, Achnanthes hauctiana - $0.25 \%$, Amphora perpusilla - $0.25 \%$, Cocconeis disculus - 
B ENTHOS

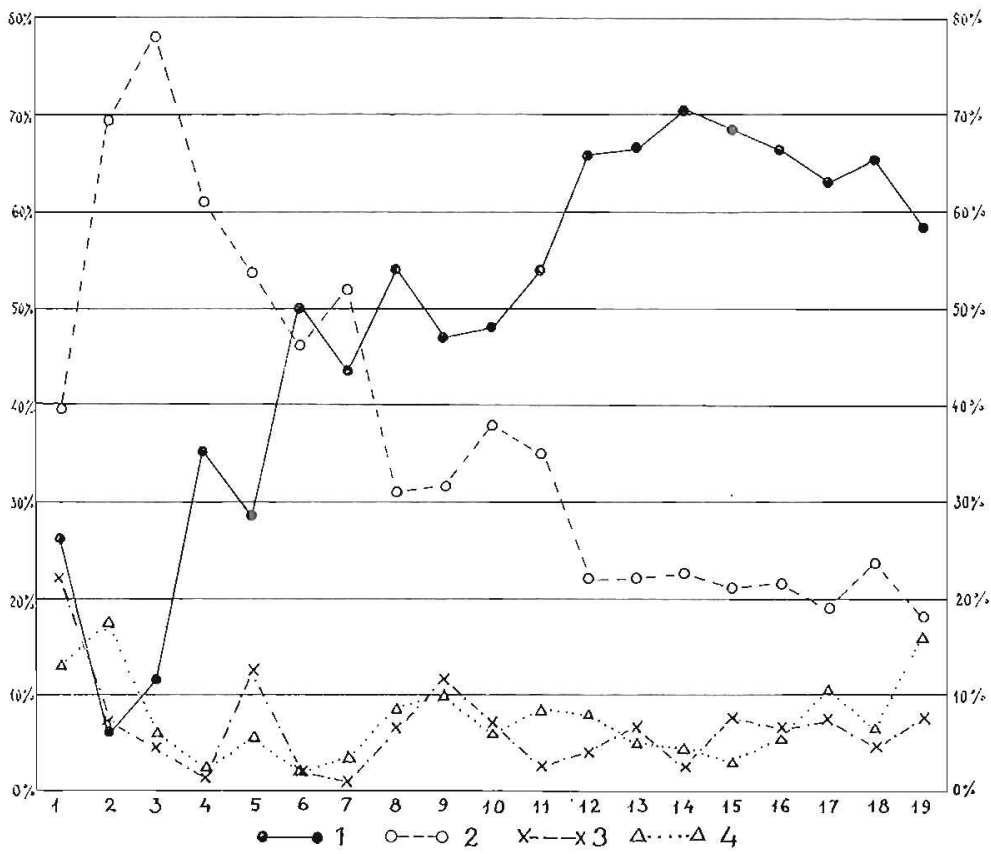

Abbildung 11. 1. Salzwassertormen. 2. Brackwasserformen. 3. Sïsswasserformen. 4. Süss-und Brackwasserformen.

$0.25 \%$, C. scutellum - $0.25 \%$, Coscinodiscus oculus ividis $-0.25 \%$, Cyclotella meneghiniana - $0.25 \%$, Evithemia turgida - $0.25 \%$, Fragilaria conslivens v. subsatina - $0.25 \%$, Fr. pinnata - $0.25 \%$, Melosina arctica $0.25 \%$, Navicula peregrina - $0.25 \%, N$. placentula f. latiuscula - $0.25 \%$ und Stauroneis anceps f. gracilis - $0.25 \%$ oder insgesamt 29 Formen. Wie aus Abb. 11 ersichtlich, machen Salzwasserdiatomeen 35.2\%, Brackwasserdiatomeen $61 \%$, Süss- und Brackwasserdiatomeen $2.2 \%$ und Süsswasserdiatomeen nur $1.6 \%$ aus.

\section{OSTSTEGEBIET}

Probe 5 (F 72 a). Diese Diatomeenprobe wurde zwischen den Inseln Hiidenmaa und Ahrenanmaa aus $108 \mathrm{~m}$ Wassertiefe entnommen. Da diese Stelle recht weit von den Ufern entfernt liegt, kamn man hauptsächlich Planktondiatomeen in der Probe erwarten. Wie Abb. 11 zeigt, machen Salzwasserdiatomeen 28.5\%, Brackwasserdiatomeen $53.5 \%$, Suiss- und Brackwasserdiatomeen $5.5 \%$ und Süsswasserdiatomeen sogar $12.5 \%$ aus, 
obschon die Probenahmestelle sehr weit ron den Ufern entfernt in der Ostsee liegt. An Diatomeen waren folgende Formen zu finden: Achnanthes taeniata - 36\%, Thalassiosira baltica - 18.5\%, Thalassiosira decipiens $13 \%$, Melosira islandica ssp. helvetica - 3.5\%, Synedra tabulata - $3 \%$, Coscinodiscus marginatus - $2.5 \%$, Cyclotella kiutzingiana - $2.5 \%$, Pyxidicula mediterranea $-2.5 \%$, Coscinodiscus lacustria - 2\%, C. radiatus $2 \%$, Cocconeis scutellum - $1.5 \%$, Melosira granulata- $1.5 \%$, Stephanodiscus hantzschii - $1.5 \%$, Cocconeis diminuta - $1 \%$, Diploneis bombus $1 \%$, und Rhopalodia gibba - $1 \%$. Alle folgenden Diatomeen belaufen sich in der Probe auf nur $0.5 \%$ : Achnanthes haukiana, A. linearis und v. pusilla, Amphora coffecueformis, A. commutata, A. ovalis v. pediculus, A. perpusilla, Cocconeis pediculus, Coscinodiscus oculus iridis, Diploneis ovalis, Epithemia zebra, E. turgida, Grammatophora marina, G. oceanica, Melosira distans, Navicula hungarica, und Nitzschia obtusa. Von den Planlitonformen kommen die ersten drei sehr reichlich vor und alle anderen recht selten.

Probe 6 (F 74 a). Diese Probe wurde westlich der Insel Hiimaa aus $162 \mathrm{~m}$ Wassertiefe entnommen und enthielt sehr viel braune Seclimentteile und sehr wenig Diatomeen. Salzwasserformen machten $50 \%$, Brackwasserdiatomeen $46 \%$, Süss- und Brackwasserformen $2 \%$ und Süsswasserdiatomeen auch $2 \%$ aus (Abb. 11). An Diatomeen waren folgende Formen zu finden: Thalassiosira baltica-34\%, T. decipiens - $18 \%$, Actinocychus ehrenbergi-14\%, Achnanthes taeniata - 10\%, Hyalodiscus scoticus - 8\%, Coscinodiscus marginalus - 4\%, C. kützingii - 1\%, Navicula cincta - $1 \%$ und Synedra tabulata - $1 \%$. Arten- und Varietätenzahl war in dieser Probe nur 12. Wahrscheinlich sind diese kleine Artenzahl und auch der Individuenreichtum von Wassertiefe und Bodenablagerungen abhängig.

Probe 7 (F 78 B). Diese Probe wurde der Ostsee nördlich der Insel Gotland aus $445 \mathrm{~m}$ Wassertiefe entnommen. Salzwasserformen machen $43.5 \%$, Brackwasserdiatomeen $52 \%$, Süss- und Brackwasserformen $3 \%$ und Süsswasserformen nur $0.5 \%$ aus oder sind praktisch völlig fehlend (Abb. 11). Einige der vorhandenen Diatomeen enthielten kein Protoplasma mehr und lagen abgestorben auf dem Meeresboden. In dieser Probe kamen folgende Formen vor: Achnanthes taeniata-29\%, Thalassiosira decipiens - $14.5 \%, T$. baltica - $12.5 \%$, Synedra tabulata - $9 \%$, Coscinodiscus marginatus - $6.5 \%$, Hyalodiscus scoticus - $5 \%$, Actinocyclus ehrenbergii - $3 \%$, Fragilaria cylindrus - $2.5 \%$, Coscinodiscus excentricus v. fasciculata $-2 \%$, C. radiatus - $2 \%$, C. kützingii - $1.5 \%$, Pyxidicula mediterranea - $1.5 \%$, Chatoceros atlanticus - $1 \%$, Cocconeis scutellum $1 \%$, Epithemia turgida - 1\%, Licmophora paradora - 1\% und Synedra. pulchella - $1 \%$. Alle folgenden Formen machten in cler Probe nur $0.5 \%$ aus: Amphora commutala, Chaetoceros muelleri, Coscinodiscus asteromhalus, C. lacustris, C. oculus iridis, C. rothii v. subsalsa, Cyclotella kiüzingiana,

$6 \quad 3854-62$ 
Fragilaria pimnata, Melosira sulcata, M. vestii, Opepthora martyi und Stephanodiscus hantzschii. Obgleich cliese Probe aus $445 \mathrm{~m}$ Wassertiefe entnommen worden war, enthielt sie insgesamt 29 Formen und Probe 6, die aus nur 162 m Wassertiefe stammte, nur 12 Arten.

Probe 8 (F 80). Diese Diatomeenprobe wurde östlich der Insel Gotland aus $179 \mathrm{~m}$ Wassertiefe entnommen und enthielt folgende Formen: Thalassiosira baltica - $22.5 \%$, T. decipiens - $18.5 \%$, Coscinodiscus radiatus $10.5 \%$, Epithemia turgida - 6\%, Actinocychus ehrenbergii - $5 \%$. Rhabdonema arcuatum - 5\%, Synedra tabulata - 4.5\%, Coscinodiscus marginatus - 4\%, Achnanthes laeniala - 3.5\%, Melosiva islandica ss]. helvetica $-3.5 \%$, Grammatophora oceanica - $3 \%$, Coscinodiscus kützingi - $2.5 \%$, C. perforatus - $2 \%$, Hyalodiscus scoticus - $1.5 \%$, Melosina granulata $1.5 \%$. M. distans - $1 \%$, Coscinodiscus lacustis - $1 \%$, Grammalophora marina v. adriatica - $1 \%$, G. marina - 0.5\%, Amphora commatata$0.5 \%$, Navicula rhynchocephala - $0.5 \%$, Nitzschia kiüzingiana - $0.5 \%$, Rhoicosphenia curvata - $0.5 \%$, Thalassionema nitzschioides - $0.5 \%$ and Thalassiosira fluviatilis - $0.5 \%$, Salzwasserdiatomeen machen in dieser Probe $54 \%$, Brackwasserformen $31 \%$, Süss- und Brackwasserformen $8.5 \%$ und Süsswasserdiatomeen sogar $6.5 \%$ aus (Abb, 11).

Probe 9 (F 81). Diese Probe wurde östlich der Insel Gotland ans $215 \mathrm{~m}$ Wassertiefe entnommen. Von den Diatomeen kamen folgende Formen vor: Thatassiosiva baltica - 24\%, T. decipiens - $19 \%$, Coscinodiscus radiatus - 6\%, Diploneis bombus - 4.5\%, Coscinodiscus rothii v. subsalsa - $3.5 \%$, Fragilaria pinnala - $3 \%$, Melosira islandica ssp; helvetica - $3 \%$, Symedra. tabulata - $3 \%$, Pyardicala medtiterranea -- $3 \%$, Coscinodiscus lacustris $2.5 \%$. Melsira granulata - 2.5\%, Coscinodiscus kibtzingi - $2 \%$, Epithemia turgida - 2\%, Grammatophora marina - $2 \%$, Opephora martin - $2 \%$, Cyclotella meneghiniana - $1.5 \%$, Fragilaria cylindrus - $1.5 \%$, Hyalodiscus scotisus - $1.5 \%$, Melosina westii - $1.5 \%$, Achnanthes taeniata - $1 \%$, Actinocyclus ehvenbergii - . \% Coscinodiscus narginatus - $1 \%$ und Stephanodiscus hantzschii - $1 \%$. Alle folgenden Diatomeen machen nur $0.5 \%$ aller Diatomeen aus: Achnanthes hauckiana, Cocconeis pediculus, Coscinodiscus oculus iridis, Cyclotella kützingiana, Diploneis smithii, Eunotia venewis, Melosiva ambigua, Navicula peregrina, Nitzschia capitellata und StepTanodiscus astraea, oder insgesamt 33 Arten und Varietäten. Diese Formen betragen zusammen $47 \%$ Salzwasserformen, $31.5 \%$ Brackwasserformen, $10 \%$ Süss- und Brackwasserformen und $11.5 \%$ Süsswasserformen (Abb. 11). Unter den Süsswasserdiatomeen sieht man liauptsächlich Melosiren.

Probe 10 (Z 290). Diese Probe stammt nicht weit westlich der Insel Gotland aus $102 \mathrm{~m}$ Wassertiefe und enthielt folgenden Formen: Achnanthes taeniata - $13 \%$, Synedra tabulata - $12 \%$, Thalassiosira decipiens $11.5 \%$, T. battica - $10 \%$, Chaetoceros muelleri-8.5\%, C. atlanticus - $6 \%$, Ac- 
tinocyclus ehrenbergii - $4 \%$, Hyalodiscus scoticus - $3.5 \%$, Coscinodiscus radiatus $-2.5 \%$, C. excentricus v. fasciculata - $2 \%$, Epithemia turgrda - $2 \%$, Fragilaria cylindrus - $2 \%$, Achnanthes hanckiana - $1.5 \%$, Cocconeis scutellum - $1.5 \%$, Amphora commulata - $1.5 \%$, Rhoicosphenia curvala - $1.5 \%$, Cocconeis diminuta - $1 \%$, Coscinodiscus lacustris - $1 \%$, C. marginatus - $1 \%, C$. kübingiana - $1 \%$, Cyclotella kiutzingiana - $1 \%$, Grammatophora oceanica - $1 \%$, Navicula anglica - 1\%, Synedra tabulatu v. fasciculata - $1 \%$. Alle folgenden Formen machen nur $0.5 \%$ aus: Amphora ovalis v. pediculus, A. perpusilla, Diatoma elongatum, Epithemia turgida r. westermanni, E. sorer, Fragilawia atomus, F. pimnata, Grammatophora marina, G. oceanica v. macilenta, Licmophora gracitis, Melosira distans, 1. gramulata, M. westii, Navicula viridula, Nitzschia dissipata, Rhoicosphenia marina, Stephanodiscus hantzschii und Cocconeis scutellum $v$, stanoneiformis. Salzwasserformen belaufen sich auf $48 \%$, Brackwasserformen auf $38 \%$, Süss- und Brackwasserformen auf $6 \%$ und Süsswasserformen auf $7 \%$ / (Abb. ] 1).

Probe 11 ("10»). Diese Probe ist SE der Insel Gotland aus $100 \mathrm{~m}$ Wassertiefe und ca. $80 \mathrm{~m}$ von der Insel entfernt entnommen worden. Aus diesel: Probe wurden folgende Diatomeen bestimmt: Thalassiosir baltica $23 \%$. T. decipiens - $14 \%$, Actinocychus ehrenbergii - $12.5 \%$, Coscinodiscus marginatus - 10.5, Epithemia turgida - 4.5\%, Coscinodiscus radiatus $-4{ }_{0}$. C. lautzingi - 3.5\%, Grammatophora marina - 3.5\%, Synedra tabulata - $9 \%$, Stephanodiscus hantzschii- $2.5 \%$, Achnanthes taeniata$2 \%$. Pyridicula medileraneae - $1.5 \%$, Coscinodiscus lacuslvis - $1 \%$, Cyclotella liülingiana - $1 \%$, Grammatophora oceanica - $1 \%$ und Rhabdonema. arcuatum - $1 \%$. Alle folgende Formen machten $0.5 \%$ aus: Amphora commulala. Cocconeis pediculus, C. sculellum, Coscinodiscus rothii v. subsalsa, Diplone is bombus, D. ovalis, Hyalodiscus scoticus, Melosiva islandica ss]. helvetica. Navicula peregrina, Rhoicosphenia curvata und Thalassionema nitzschioides. Salzwasserdiatomeen machen $54 \%$, Brackwasserformen $35 \%$, Sü̈ss- und Brackwasserformen 8.5\% und Süsswasserdiatomeen nur $2.5 \%$ aus (Abb, 1]). An den Diatomeen ist zu erkemnen, dass die Flüsse keine Süssrasserformen mehr bis dieser Stelle transportieren können und deshalb die Salzwasserformen überhand nehmen.

Probe 12 ("15»). Diese Diatomeenprobe ist ca. $50 \mathrm{~km}$ NE der Insel Bornholm gehoben worden und enthielt folgende Formen:Thalassiosira batlica - $15 \%$, T'. decipiens - 9\%, Diploneis bombus - 9\%, Grammatophora oceanica $-7 \%$, G. marina - 6.5\%, Rhabdonema arcuatum- 6.5\%, Coscinoliscus marginatus - 5\%, Synedra tabulata - 5\%, Diploneis inlerrupta - $3 \%$, Achnanthes haukckiana - $2.5 \%$, Coscinodiscus radiatus $2.5 \%$, Eprithemia turgida - 2.5\%, Actinocychus ehrenbergii-6\%, Cocconeis csutellum - $1.5 \%$, Coscinodiscus kittingi - $1.5 \%$, C. lacustris - $1.5 \%$, 
Melosira sulcala-1.5\%, Thalassionema nitzschioides - $1.5 \%$, Diploneis smithii - $1 \%$, Epithemia zebra - $1 \%$, Fragilaria pinnata - $1 \%$, Hyalodiscus scoticus - $1 \%$ und Opephora martyi - 1\%. Alle folgende Formen beliefen sich nur auf $0.5 \%$ : Achnanthes taeniala, Amphora ovalis, Cocconeis pediculas, Cyclotella kiützingiana, C. meneghiniana, Cymbella prostrata, C. sinuata, Diatoma elongatum, Diploneis puella, Epithemia turgida v. westermanni, Glyphodesmis distans, Mastogloia smithii, Melosira distans. Navicula jentzschii und Stephanodiscus dubius. Salzwasserdiatomeen machten in dieser Probe $66 \%$, aus Brackwasserdiatomeen $22 \%$, Süss- uncl Brackwasserdiatomeen $8 \%$ und Süsswasserdiatomeen nur $4 \%$ (Abb. 11).

Probe 13 (\$17)). Diese Probe wurde nicht weit westlich der Insel Bornholm entnommen und enthielt folgende Diatomeen: Thalassiosira decipiens $-21 \%$, T. baltica - $9 \%$, Synedra labulata - $7 \%$, Sceletonema costatum $-5 \%$, Achnanthes taeniata - $4.5 \%$, Cocconeis scutellum - 4\%, Grammatophora oceanica - 4\%, Diploneis bombus - 3.5\%, Rhabdonema arcuatum - $3.5 \%$, Achnanthes hauckiana - $3 \%$, Actinocyclus ehrenbergii - 3\%, Coscinodiscus kiutzingi-3\%, Melosira sulcata - $3 \%$, Fragilaria cylindrus$2 \%$, Hyalodiscus scoticus - $2 \%$, Opephora marlyi $-3 \%$, Diploneis interrupta - $1.5 \%$, D. smithii - $1.5 \%$, Epithemia turgida - $1.5 \%$, Fragilaria pinnata - $1.5 \%$, Cocconeis diminuta - $1 \%$, Coscinodiscus marginatus $1 \%$, und Grammalophora marina - $1 \%$. Alle folgenden Diatomeen belaufen sich auf nur $0.5 \%$ der in der Probe anzutreffenden Formen: Achnanthes linearis v. pusilla, Anphora commutata, A. ovalis und v. pediculus, Coccone is disculus, Coscinodiscus marginatus, C. rothii v. subsalsa, Cyclotella meneghiniana, Cymbella sinuata, Diploneis interrupla v. heeri, D. elliptica, Epithemia. zebra, Fragilaria construens v. venter, Glyphodesmis distans, Navicula rhynchocephala, $N$. scutelloides, $N$. tuscula $\%$. obtusa, Nitzschia punctata, Synedra labulata v. acuminata, Thalassionema nitzschioides und Grammatophora marina. Salzwasserformen machten $66.5 \%$ aus, Brackwasserformen $22 \%$, Süss- und Brackwasserformen $5 \%$ und Süsswasserformen 6.5\% (Abb.11).

Probe 14 ("18»). Diese Probe wurde westlich der Insel Bornholm aus $47 \mathrm{~m}$ Wassertiefe entnommen und enthielt folgende Diatomeen: Thalassiosira decipiens - $16 \%$, Synedra tabulata - 9\%, Achnanthes taeniata - $6 \%$. Diploneis bombus - 5.5\%, Grammatophora oceanica - 5.5\%, Thalassiosina baltica - 5.5\%, Cocconeis scutellum - 5\%, Coscinodiscus mavinatus $5 \%$, Graminatophora marina - 4.5\%, Rhabdonema arcuatum - $4 \%$. Scelelaria cylindrus - $2.5 \%$, Melosira sulcata - 2.5\%, Aclinocyclus ehrenbergii. $-1.5 \%$, Chatoceros allantica - $1.5 \%$, Coscinodiscus kiutzingi - $1.5 \%$ : Epithemia turgida - $1.5 \%$, Glyphodesmis distans - $1.5 \%$, Rhabdonema mimutum - $1.5 \%$, Chaetoceros muelleri-1.5\%, Fragilaria pinnata - $1 \%$, Hyalodiscus scoticus - $1 \%$. Alle folgenden Formen machen nux $0.5 \%$ aus: Achnanthes linearis, Amphora ovalis var. pediculus, Bacillaria paradoxa, 
Cocconeis disculus, C. pediculus, Coscinodiscus lacustris, C. oculus iridis, C. radiatus, Dimerogramma fulvum, Diploneis interrupta und v. heeri, Epithemia turgida $\mathrm{v}$. westermanni, Fragilaria brevistriata, $F$. construens v, venter, Cyclotella meneghiniana, Melosira juergensi, Navicula pygmaea, Nitzschia obtusa, Opephora marina, Plagiogramma staurophorum, Rhoicosphenia curvata und Thalassionema nilzschioides.

Salzwasserdiatomeen belaufen sich auf $70.5 \%$, Brackwasserdiatomeen auf $22.5 \%$, Süss- und Brackwasserformen auf $4.5 \%$ und Süsswasserdiatomeen auf nur $2.5 \%$ (Abb. 11).

Probe 15 (»20»). Die Tiefe des Wassers betrug $47 \mathrm{~m}$. In dieser Probe fanden sich folgende Diatomeen: Thalassiosira decipiens - 19.5\%, Cocconeis scutellum - 7.5\%, Synedra tabulata - 7.5\%, Achnanthes taeniata - $5.5 \%$, Rhabdonema arcuatum - $5.5 \%$, Thalassiosira baltica - 6\%, Diploneis bombus- $4.5 \%$, Fragilaria cylindrus - 3.5\%, Diploneis smilhii - $3 \%$, Achnanthes haucliana-3.5\%, Coscinodiscus marginatus - $2.5 \%$, Grammatophora oceanica - 2.5\%, Actinocyclus ehrenbergii - 2\%, Coccone is diminula $-2 \%$, Fragitaria pinnata - 2\%, Coscinodiscas kütringi - $1.5 \%$, Grammatophora marina - $1.5 \%$, Hyalodiscus scoticus - $1.5 \%$, Amphora commulata $-1 \%$, Coscinodiscus radiatus - $1 \%$, Cyclotella kützingiana - $1 \%$, Dimerogramma minor - $1 \%$, Melosira distans - $1 \%$, Navicula peregrina - $1 \%$, Opephora manty $-1 \%$, Rhabdonema minutum - $1 \%$, Sceletonema costatum - $1 \%$. Alle folgenden Formen machen nur $0.5 \%$ aus: Achnanthes brevipes, Amphora colleaelormis, A, ovalis v. pediculus, Bacillaria paradora, Chaeloceros atlantica, Cocconeis pediculus, Dimerogramma marina, Diploneis didyma, D. internuta v. heeri, D. puella, Epithemia hugida, Cocconeis disculus, Navicula placentula, Nitzschia punctata v. coarclata, Navicula digitoradiata, Nitzschia sigma, Opephora marina und Pyxidicula mediterranea.

Salzwasserdiatomeen betrugen zusammen $68.5 \%$, Brackwasserdiatomeen $21 \%$, Süss- und Brackwasserdiatomeen $3 \%$ und Süsswasserdiatomeen $7.5 \%(A b b .11)$.

Probe 16 ("21》) aus $45 \mathrm{~m}$ Wassertiefe. Folgende Diatomeen kamen vor: Cocconeis scutellum - $11.5 \%$, Synedra tabulata - $10.5 \%$, Thalassiosira decipiens - $9 \%$, Rhabdonema arcuatum - 7.5\%, Thalassiosira ballica - $6 \%$ : Achnanthes hauckiana - 5.5\%, Diploneis bombus - 5\%, Grammatophora oceanica - 3.5\%, Actinocychus ehrenbergii - 3\%, Epithemia turgida - $3 \%$, Rhabdonema minutum - $3 \%$, Achnanthes taeniata-2\%, Coscinodiscus marginatus - 2\%, Opephora martyi - 2\%, Amphora commutata - $1.5 \%$, Diploneis didyma - $1.5 \%$, D. smithii - $1.5 \%$, Fragilaria pinnata - $1.5 \%$, Grammatophora oceanica v. macilenta - $1.5 \%$, Thalassionema nitzschioides $-1.5 \%$, Amphora ovalis - $1 \%$, Coscinodiscus radiatus - $1 \%$, Diploneis puella - $1 \%$, D. smithii v. pumila - $1 \%$, Grammatophora marina - $1 \%$ und Navicula peregrina - $1 \%$. Alle folgende Formen machen nur $0.5 \%$ 
aus: Achnanthes breipes, Amphora cofleaeformis, A. ovalis v. pediculus, Cocconeis diminuta, $C$. pediculus, $C$. quarnerensis, Coscinodiscus külzingi. Diploneis coffaeiformis, D. elliptica, D. fusca, D. internpta und v. heeri, Fragilaria cylindrus, Mastogloia smithii, Navicula halophila, $N$. humerosa, $N$. placentula und f. latiuscula, N. pygmaea, Nitzschia navicularis, Opepthora marina, Rhoicosphenia marina und Rhopalodia gibberula.

Zusammen Salzwasserformen 66.5\%, Brackwasserformen 21.5\%. Süissund Brackwasserformen 5.5\% und Süsswasserformen 6.5\% (Abb. 11).

Probe 17 ("16») aus $98 \mathrm{~m}$ Wassertiefe am Meeresboden entnommen. Enthielt folgende Diatomeen: Thalassiosira decipiens $17 \%$, Synedra tabulata $9.5 \%$, Thalassiosira ballica $7.5 \%$, Cocconeis scutellum $4.5 \%$, Actinocyclus ehrenbergii $4 \%$, Fragitaria pinnata $4 \%$, Achnanthes hanckiana $3.5 \%$, Epithemia twrida $3 \%$, Grammatophora oceanica $3 \%$, Coscinodiscus kütaingi $4 \%$, Diploneis bombus $2.5 \%$, Hyalodiscus scoticus $2.5 \%$, Rhabdonema arcuatum $2.5 \%$, Amphora commutata $2 \%$, Cocconeis diminuta $2 \%$, Fragilaria cylindrus $2 \%$, Grammatophora marina $2 \%$, Sceletonema costatum $2 \%$, Amphora perpusilla $1.5 \%$, Cocconeis disculus $1.5 \%$, Coscinodiscus radiatus $1.5 \%$, Cyclotella kützingiana I \%, Navicula peregrina f. minor $1 \%$, Rhabdonema minutum $1 \%$, Thalassionema nitzschioides $1 \%$. Alle folgenden Formen erreichten nur $0.5 \%$ : Achnanthes microcephala, Cocconeis pediculus, Chatoceros atlanticus, Coscinodiscus excentricus v. fasciculata, C. oculus iridis. Dimerogramma fulvum, D. marinum, Diploneis didyma, D. elliptica, D. interrupta und v. heeri, D. smithii, Epithemia zebra, E. turgida v. westermannii, Grammatophora oceanica v. macilenta, Melosira sulcata, Navicula digitoradiata, N. menisculus, $N$. palpebralis, $N$. peregrina, $N$. tuscula, Nitzschia apriculata, $N$. frustulum v. subsalina, Opephora marina, Plagiogramma staurophorum, Pyxidicula mediterranea und Rhoicosphenia curvala oder insgesamt 53 Formen.

In dieser Probe betrugen Salzwasserdiatomeen $63 \%$, Brackwasserdiatomeen $19 \%$, Süss- und Braclewasserdiatomeen $10.5 \%$ und Süsswaswasserdiatomeen $7.5 \%$.

Probe 18 (19y) wurde aus $47 \mathrm{~m}$ Wassertiefe entnommen und enthielt folgende Formen: Thalassiosira decipiens $14.5 \%$, Diploneis bombus $7.5 \%$, Synedra tabulata $7 \%$, Thalassiosiva baltica $7 \%$, Achnanthes taeniata $6.5 \%$, Grammatophora oceanica $5.5 \%$, Fragilaria cylindrus $4.5 \%$, Rhabdonema arcuatum $4.5 \%$, Coscinodiscus marginatus $3.5 \%$, Melosira sulcala $3.5 \%$, Achnanlhes hauckiana $3 \%$, Amphora commulata $2.5 \%$, Cocconeis scutellum. $2.5 \%$, Epithemia turgida $2 \%$, Actinocyclus ehrenbergii $1.5 \%$, Chactoceros muelleri $1.5 \%$, Diploneis smithii $1.5 \%$, Grammatophora marina $1.5 \%$. Rhabdonema arcuatum v. robusia $1.5 \%$, Amphora ovalis v. pediculus $1 \%$, Coscinodiscus oculus iridis $1 \%$, Hyalodiscus scoticus I \%, Rhoicosphenia curvata $1 \%$. Alle folgenden Formen machten nur $0.5 \%$ aus: Achnanthes brevipes, 
Amphora giganlea, A. ovalis, A. perpusilla, Cocconeis costala, C. disculus, Coscinodiscus liützingi, C. lacustris, C. radialus, C. rothii v. subsalsa, Cymbella prostrata, C. sinuala, Diptoneis elliptica, D. interrupta, Endictya oceanica, Glyphodesmis distans, Navicula humerosa, N. peregrina, Nitzschia obtusa, Opephora marina, O. martyi, Pyxidicula mediterranea, Sceletonema costatum und Stephanodiscas hantzschii oder insgesamt in dieser Probe 48 Arten und Varietäten.

Salzwasserdiatomeen betragen $65.5 \%$, Brackwasserdiatomeen 23.5\%: Süss- und Bracliwasserdiatomeen $6.5 \%$ und Süsswasserdiatomeen $4.5 \%$ (Abb. 1I).

Die Benthosdiatomeen aus Probe 19 sind schon in den Ausführungen ¿ber die Untersuchungsmethodik näher beschrieben worden.

In den Diatomeenproben, die in der Umgebung der Insel Bornholm entnommen worden sind, kommen mehrere Salzwasserdiatomeen vor, die weiter nordwärts nicht mehr vorhanden sind oder langsam verschwinden. Diese Erscheinung bestätigt, dass das Wasser mit seinen Strömungen aus der Nordsee diese Formen mitbringt, die dann in den Proben da rorkommen. wo sie eigentlich nicht mehr gut gedeihen können. 


\section{Abhängigkeit der am Meeresboden vorkommenten ökologischen Diatomeengruppen von der Salzkonzentration des Wasser's}

Am besten sieht man die Abhängigkeit der Diatomeen von der Salzkonzentration des wassers, wenn man die in clen Diatomeenproben festgestellen Formen in ökologische Gruppen einteilt. Derartige Gruppen sind: 1. Salzwasserdiatomeen, 2. Brackwasserdiatomeen, 3. Süss- und Brackwasserdiatomeen und 4. Süsswasserdiatomeen. Zu der letzten Gruppe gehörende Diatomeen wachsen gewöhnlich nur in den Binnenseen und Flüssen, von wo aus sie in das Untersuchungsgebiet gelangt sind, und da haben sie nicht wachsen kömnen.

In Abb. 2 sind die Salzkonzentrationen des Oberflächenwassers und des am Meeresboden vorhandenen Wassers graphisch wiedergegeben. In Abb. 11 sind die ökologischen Diatomeengruppen dargestellt. Bei gegenseitigem Vergleich dieser beiden Abbildungen, sieht man, dass die Salzkonzentration und die Salzwasserdiatomeengruppe in den nördlichen Teilen des Bottnischen Meerbusens recht gering sind. In den Diatomeenproben aus diesen Teilen erreichen die Brackwasserdiatomeen grosse Individuenzahlen, sie haben da optimale Wachstumsbedingungen gefunden. Salzwasserdiatomeen dagegen lxommen sehr selten vor, und die Arten haben geringe Individuenzahlen, denn sie können in so niedrigen Salzlonzentrationen nicht gedeihen.

Erst in clen mittleren Teilen des Bottnischen Meerbusens, wo die Salzkonzentration des Wassers deutlich steigt, mehmen die Brackwasserdiatomeen in ihrem Reichtum ab und die Salzwasserdiatomeen deutlich zu. Besonders gut zeigt sich diese Erscheinung bei Station 9 (F 74), wo die Salzwasserformen grössere Prozentzahlen erreichen als die Brackwasserdiatomeen.

Süsswasserdiatomeen kommen in Probe 1 recht individuenreich vor, nehmen aber nach Süden hin ab und erscheinen dann in allen Diatomeenproben in kleinen Mengen (Abb. 11). Beinahe ähnlich treten auch Brackund Sïsswasserdiatomeen in den Proben hervor. Sie haben ebenfalls die höchsten Prozentsätze im Norden und auch bei der Insel Bornholm, wohin sie wahrscheinlich aus den Flüssen gelangt sind, denn am Meeresboden ist 
der Salzgehalt so hoch, dass sie in dieser Konzentration nicht wachsen können (Abb. 2).

In der Ostsee nehmen die Salzwasserdiatomeen in den Indivichenzahlen zu, je weiter man nach Süden kommt. Die Brackwasserformen aber nehmen deutlich in den Zahlen ab, je salzhaltiger das Wasser auf dem Meeresboden in den südlichen Teilen des Baltischen Meeres wird (Ablu. 11). Die Kurve in Abb. 2 lässt erkennen, dass die Salzkonzentration am Meeresboclen sehw stark schwankt. Im Oberflächenwasser ist die Salzkonzentration in der Ostsee beinahe ähnlich und steigt langsam von der Insel Gotland an südwärts. Die Kurve für die Salzwasserdiatomeen am Meeresboden ähnelt viel mehr der Salzgehaltkurve des Oberflächenwassers (Abb. 2 und 11).

Zu den Salzwasserdiatomeen unter den Benthosformen werden folgende Arten und Varietaiten gezählt: Achnanthes brevipes Agardh, A. hauckiana Grun., Actinocychs ehrenbergii Ralfs, Chaetoceros atlanticus Cleve, Ch. muelleri Lemm., Cocconeis quanerensis Grum., C. scutellum. Ehr. und v. stanroneiformis W. Smith, Coscinodiscus asteromphalus Ehr., O. excentricus Ehr. v. fasciculata Hust., C. kützingii A. Schmidt, C. marginatus Ehr., C. oculus irdis Ehr., C. perforatus Ehr., C. radiatus Ehr., Dimerogramma futva (Greg.) Ralfs, D. maninum (Greg.) Ralfs, Diploneis bombus Ehx., D. coffaeiformis (A.S.) Cleve, D. didyma Ehr., D. fusca (Greg.) Cleve, D. internupta (Kütz.) Cleve, D. interupla v. heevi (Pant.) Hust., D. smithii (Bréb.) Cleve, D. smithii var. mumila (Grun.) Hust., Endictya oceanica Ehr., Fragilaria cylindrus Grun., Glyphodesmis distans (Greg.) Grum., Grammatophora manina (Lyngbye) Kütz., G. manina v. adriatica Grun., G. oceanica (Ehr.) Grun., Hyalodiscus scoticus (Kütz.) Grun., Licmophora gracilis (Ehr.) Grun., L. paradoxa (Lyngbye) Agardh, Melosina arctica (Ehr.) Dickie, ML. sulcata (Elur.) Kütz., M. westii W. Smith, Navicula digitoradiata (Greg.) A. Schmidt, N. humerosa Bréb., N. peregrina (Ehr.) Kütz,. Nitzschia apiculata (Greg.) Grun., N. obtusa. W. Smith, $N$. punctata (W. Smith) Grun., N. punctata v. coarctala Grun., N. scalaris (Ehr.) W. Smith, Opephora marina (Greg.) Petit, Plagiogramma stanophorum (Greg.) Heiberg, Pyxidicula mediterranea Grun., Rhabdonema arcuatum (Agarclh) Kü̈tz., R, minutum Kütz., Rhopalodia gibberula (Elxr.) O. Müll., Rhoicosphenia marina (W. Smith) M. Schmidt, Sceletonema costatum (Grev.) Cleve, Stauroneis salina W. Smith, Survella striatula Turpin, Thalassionema nitzschioides Grum., Thalassiosira decipiens (Grun.) Joergensen oder insgesamt 58 Arten und Varietäten, von denen sogar 22 Formen nur ein einziges Mal vorhanden waren.

An Brackwasserdiatomeen ] samen folgende Formen vor: Achnanthes laeniala Grun., Amphora cofleaeformis Agardh, A. commutata Grun., Bacillaria. paradora Gmelin, Mastogloia smithii Thwaites, M. smithii v. amphicephala. Grum., Navicula crucicula (W. Smith) Donkin, N. Inmerosa Bréb. v. lata Mölder, Synedra tabulata (Agardh) Kütz., S. tabulata v. fasciculata (Kütz.) 
Grun., Thalassiosira ballica (Grum.) Ostenfeld oder insgesamt 11 Arten und Varietäten, von denen 4 Formen nur ein einziges Mal vorhanden waren.

An Süss- und Brackwasserdiatomeen zeigten sich folgende Formen: Achnanthes dispar Cleve, A. lemmermannii Hust., $A$, linearis W. Smith v. pusilla Grun., Caloneis amphisbaena (Bory) Cleve, Cocconeis pediculus Ehr. Coscinodiscus lacustris Grun., Cyclotella meneghiniana Kütz., Cymebella lacustris (Agardly) Clere, C. prostrata (Berkeley) Cleve, Diatoma elongatum Agardh, Diploneis ovalis (Hilse) Cleve, Evithemia soren Kütz., E. Lurgida (Ehr.) Kütz., E. zebra (Ehr.) Kütz., Fragilavia pinnata Ehr., Melosira varians Agardh, Navicula cincta (Ehr.) Kütz., $N$. menisculus Schumann, $N$. pygmaea Kütz., $N$. rhynchocephala Kütz., $N$. viridula Kütz., Nitzschia capitellata Hust., N. frustulum Kütz. v. subsalina Hust., N. hungarica Grun., Rhoicosphenia curvata (IKütz.) Grun., Rhopalodia gibba (Ehr.) O. Müller, R. gibba v. ventricosa (Ehr.) Grun., Stephanodiscus hantaschii Grun., Synedra. pulchella Küitz., Thalassiosira fluviatilis Hust. oder insgesamt 30 Arten und Varietäten, ron clenen 11 nur in einer Probe erschienen.

An Süsswasserdiatomeen fanden sich folgende Formen: Achnanthes kryophila Petersen, A. linearis W. Smith, A. microcephala Kütz., A. minutissima Kütz., A. saronica Krasske, Amphriplewra pellucida Kütz., Amphora ovalis Kütz., A. ovalis r. pediculus Kütz., A. perpusilla Grun., Anomoeoneis exilis (Kütz.) Cleve, Asterionella formosa Hassall, Cocconeis dimimula. Pant., C. disculus Schumann, Cyclotella kiützingiana Thwaites, Cyclotella ocellata Pant., Cymbella affinis Kütz., C. aspera C. helvetica Kütz., C. sinuata Greg., Diploneis elliptica (Kütz.) Cleve, D. puella (Schumann) Cleve, Eunotia veneris (Kuitz.) O. Müller, Fragilaria atomus Hust, F. brevistriata Grun., F. construens (Ehr.) Grum., F. construens v. venter (Ehr.) Grun., F. intermedia Grum., Melosina ambigua (Grun.) O. Nüller, M. distans (Elur.) Kütz., M. gramulata (Elnr.) Ralfs, M. islandica O. Müller ssp. helvetica O. Müller, Navicula anglica Ralfs, $N$. hungarica Grun., $N$. inflata Donkin, $N$. jentzschii Grun., N. lucidula Grun., N. placentula (Elır.) Grun., N. placentula $v$. jenisseyensis (Grun.) Meister, $N$. placentula f. latinscula (Grun.) Meister, $N$. platystoma Ehr., $N$. scutelloides W. Smith, $N$. tomeensis Cleve, N. tuscula (Ehr.) Grum., N. tuscula f. obtusa Hust., Nitzschia acula Hantzsc $N$. amphibia Grun., $N$. dissipata (Kiitz.) Grun., $N$. fonticola Grun., $N$. gracilis Hantzsch, $N$. külzingiana Hilse, $N$. stagnorum Rabenh., Opephora martyi Héribaud, Stawoneis anceps Ehr. f. gracilis (Ehr.) Cleve, S. anceps v. hyalina Brum et Peragallo, Stephanodiscus astraea (Ehr.) Grun., S. astraea v. minutula (Kütz.) Grun., Synedra ulna (Nitzsch) Ehr., Tabellaria fenestrata (Lyngbye) Kütz., T. flocculosa (Roth) Kütz. oder insgesamt 59 Arten und Varietäten, die alle zufällig auftraten. Alle obengenannten Süsswasserformen können im Untersuchungsgebiet nicht gedeihen und sind von den Flüssen in das Meer verschleppt, worden. 


\section{Verbreitung der Benthosiliatomeen im Untersuchungsgebiet}

Obgleich in den am Meeresboden gesammelten Diatomeenproben insgesamt 158 Arten, Varietäten und Formen festgestellt worden sind, haben nur einige Formen in allen Proben so grosse Individuenzahlen erreicht, dass sie graphisch in einem Diagramm wiedergegeben werden können. Zu diesen seltenen Diatomeen gehören Thalassiosira ballica, Actinocychus ehrenbergii, Achnanthes taeniata and Cocconeis scutellum (Abb. 12). Wie aus dieser Abbildung zu ersehen, lrommen beide Brackwasserdiatomeen, die auch Planktonformen sind, sehr reichlich in den Bodemproben vor, die aus dem Bottnischen Meerbusen herrühren. Ihre maximale Entwicklung erreicht Thalassiosina ballica bei Station 3 (F 26 a), wo sie $73 \%$ aller beobachteten Diatomeen ausmacht. Grosse Individuenzahlen hatt sie auch bei den Stationen 1 (F 12) und 2 ( $F 26$ a) mit 35 und $58 \%$.

Nach Abb. 12 wäre olne weiteres zu schliessen, dass Thalassiosira baltica ihre optimalen Wachstumsbedingungen in clen nördlichen Teilen des Bottnischen Meerbusens gefunden hätte. So verhält es sich aber nicht. Diese Brackwasserdiatomee ist eine typisehe Planktonform und kann auf dem Mreeresboden nicht gedeihen. Wie schon früher aus Abb. 10 erkannt, kommt sie im Plankton nur in den südlichen Teilen des Bottnischen Meerbusens und in den nördlichen Teilen des Baltischen Meeres reichlich vor. Dass sie auf dem Meeresboden in den nördlichen Teilen des Bottnischen Meeres grosse Individuenzahlen erreicht hat, ist darauf zurückzuführen, class sie dort wegen des Salzmangels nicht mehr wachsen kann so dass sie abstirbt und jetzt reichlich in den Diatomeenproben des Meeresbodens wahrzunehmen ist. Bei der Untersuchung war festzustellen, dass die Zellen kein Chlorophyll mehr enthielten und nur leere Schalen vorlagen. Weiter nach Süden zu kommt sie in den Bodenproben bis nach der Insel Bornholm meln oder weniger häufig vor: Ein Vergleich von Abb. 10 mit Abb. 12 zeigt, dass diese Planktondiatomeen im Plankton des Baltischen Meeres nur in den nördlichen Teilen reichlicher vorkommen, aber in den aus den sücllichen Teilen eingebrachten Proben völlig schwinden oder nur sehr niedrige Prozentsätze erreichen. Dies Erscheinung erweist, class sie ebenfalls grössese Salzkonzentrationen nicht vertragen lkönnen und deshalb auch in den Bo- 


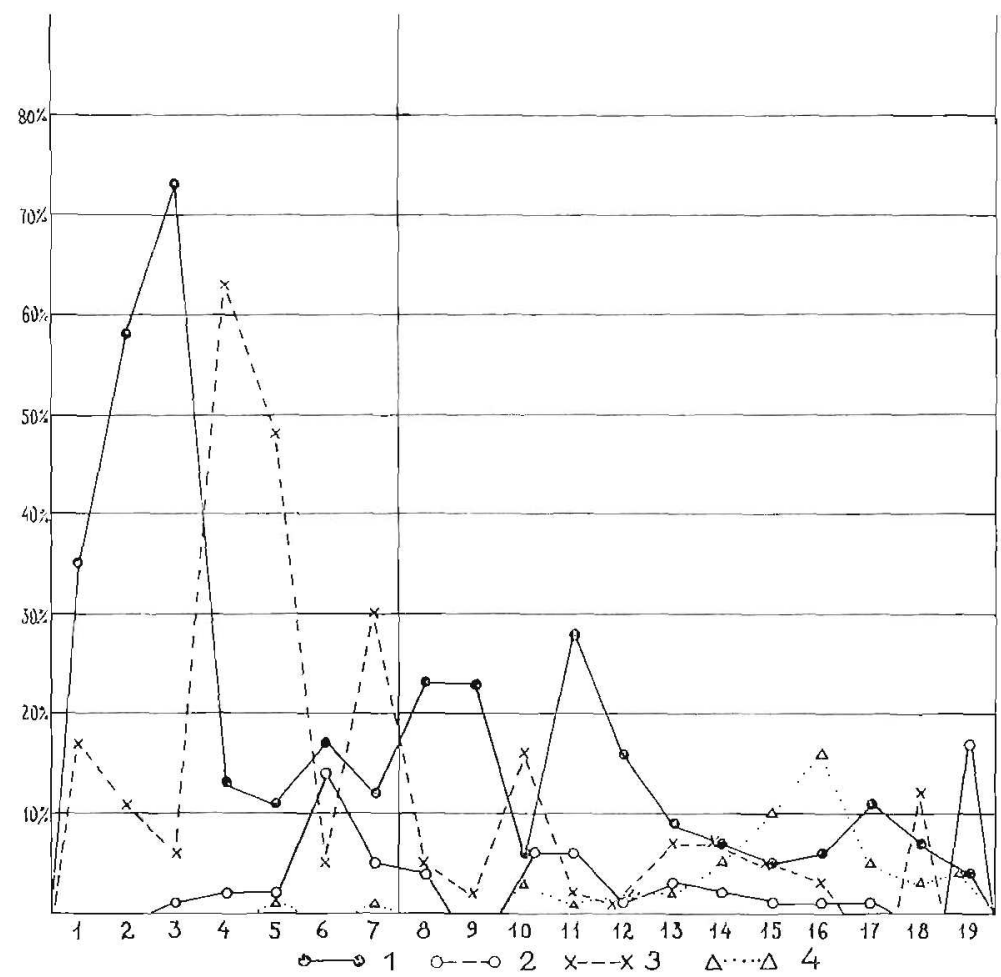

Abbildung 12. 1. 'Llatassiosira balticn. 2. Actinocvelus ehrenberoii. 3. Achmanthes taeniata. 4. Cocconeis scutellum.

denproben leere Schalen vorhanden sind. Aus diesen Ergebnissen geht dentlich hervor, dass Thalassiosira ballica nur in Wasser mit einem Salzgehait von $4 \%$ bis $6 \%$ gut gedeihen kann. Wenn aber die Salzkonzentration höher oder niedriger als diese Zahlen ist, geht sie zugrunde.

Die andere Brackwasserdiatomee erreicht ihre maximalen Individuenzahlen bei den Stationen 4 (F 52 a) und 5 ( $F$ F a) oder südlicher als die Diatomee Achnanthes taeniata (Abb. I2). Auch an den anderen Stellen im nördlichen Ende des Bottnischen Meerbusens bis nach cler Insel Bornholm kommt sie mehr oder weniger häufig in den Diatomeenproben vor, die am Meeresboden entnommen worden sind. Nach diesen Ergebnissen wäre anzunehmen, dass sie in Wassel mit einem Salzgehalt von $5 \%$ bis $10 \%$ optimale Wachstumsbedingungen gefunden hätte. Wenn wir wieder mit den Befunden im Plankton vergleicht, wo sie eigentlich wächst, dann sehen wir, dass sie im Plankton nur in clen nördlichen Teilen des Bottnischen Meerbusens wächst, wo clas Wasser eine Salzkonzentration von $3 \%$ bis $6 \%$ aufweist (Abb. 10). Auch in der Pojo-Bucht kam sie im Frühling im Plank- 
ton individuenreich in Wasser mit 4 bis $6 \%$ Salz vor (Halme und Mötoder 1958). Dass diese Diatomee auf dem Meeresboden überall vorhanden ist, bestätigt, dass sie in Wasser, dessen Salzkonzentration deutlich über $6 \%$ steigt, nicht wachsen kann, so dass sie eigentlich eingeht und an den Boden sinkt (Abb. 12).

Die dritte am Meeresboden reichlich vertretene Diatomee, die zu den Salzwasserformen gehört, ist Actinocyclus ehrenbergii (Abb. 12). Sie erreicht in keiner Probe so grosse Individuenzahlen wie die beiden obengenannten Formen. Die grössten Individuenzahlen kommen in Proben vor, die den. nördlichen Teilen der Ostsee entstammen. Sehr selten findet man sie noch im Bottnischen Meerbusen und in den südlichen Teilen des Baltischen Meeres (Abb. 12). Da diese Diatomee im Plankton wächst, kommt sie im Plankton nur im Baltischen Meere vor, und in den Meeresbuchten kann man sie nur zufällig hier und da in einigen Individuen finden (Abb. 10). Sie verlangt für ihr Gedeihen wenigstens $7 \%$ Salz im Wasser, und alle auf clem Meeresboden anzutreffenden Exemplare sind schon im Plankton abgestorben und erst danach auf den Boden gesunken.

Die vierte in den Proben reichlich auftretende Diatomee ist Cocconeis scutellum, die aber nur in den südlichen Teilen der Ostsee in den Bodenproben reichlicher vorkommt (Abb. 12). Da diese Diatomee in den Ufergebieten eine Aufwuchsform ist, hat sie sich einzig bei der Station 15 (»11») nur einmal im Plankton gezeigt. Da sie an den fimischen Meeresküsten verbreitet ist, lässt sich anhand der Salzlkonzentration des Wassers nicht ausmachen, wo sie optimale Wachstumsbedingungen lat.

In den Bodenproben fanden sich noch häufiger, abel nie in höheren Individuenzahlen die Diatomeen Achnanthes hauckiana, Coscinodiscus kützingii, C. marginatus, C. radiatus, Diploneis bombus, D. smithii, Fragilaria cylindrus, Grammatophora marina, G. oceanica, Hyalodiscus scoticus, Rhabdonema arcuatum, Thalassiosira decipiens und Synedra tabulata, von denen die letztgenannte eine Brackwasserform ist. Alle anderen aber gehören zu den Salzwasserdfatomeen. Insgesamt kamen im untersuchungsgebiet nur 15 Formen von den 158 vorhandenen Diatomeen häufiger auf dem Meeresboden vor: Diese Zahl ist eigentlich sehr gering und macht sogas: weniger als $10 \%$ aus. Auch fehlen auf dem Meeresboden beinahe alle im Plankton individuenreich vorhandenen Chaeloceros -Arten. Da diese Diatomeen zarte Zellwände haben, lösen sie sich wahrscheinlich schon im Wasser auf, bevor sie an den Boden gelangen. 


\section{Vergleich zwischen Plankton- und Benthosdiatomeen}

Der Unterschied zwischen Plankton- und Benthosdiatomeen ist in der Ostsee und im Bottnischen Meerbusen eigenlich sehr gross. Im Plankton kommen gewöhnlich in einer Probe nur 3 bis 11 Arten und Varietäten vor (Abb. 13). In den Diatomeenproben derselben Stellen, an denen die Planktoproben gesammelt worden sind, finden sich in den an Meeresboden entnommen Proben 30 bis 50 Formen, unter denen einige Diatomeen, die im Plankton reichlich vorhanden sind, am Boden völlig fehlen.

Bei der Station 2 (F 12) belief sich die Artenzahl in der Probe anf 11 und fiel dann nach Süden hin bei der Station T 81 auf 3. Ausser den schon früher beschriebenen Arten Thatassiosira baltica und Achnanthes taeniala kamen im Plankton Chatoceros wighamii, Ch. borealis, Ch. gracilis, Ch. holsaticus und $\mathrm{Ch}$. muellerii sehr individnenreich vor. Eine Ausnahma bildete

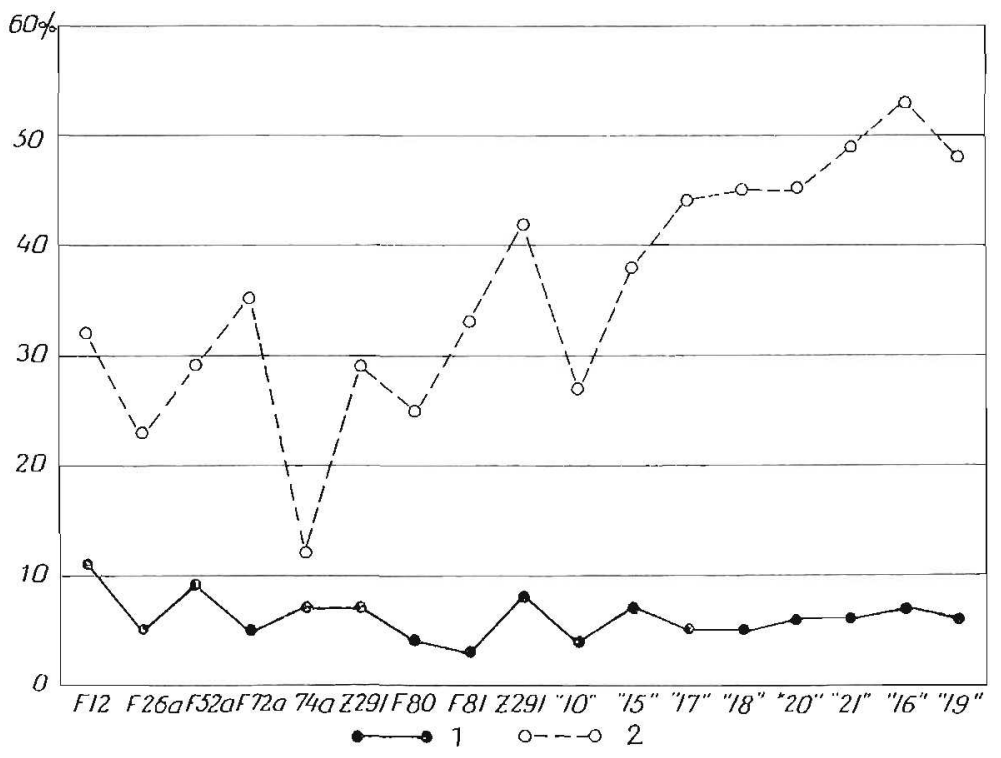

Abbilkung 13. 1. Planktondiatomeen. 2. Benthosdiatomen. 
die Probe bei der Station F 81, wo nur Actinocyclus ehrenbergii, Chaetoceros borealis und Thalassiosira ballica auftraten (Abb. 13). Von der Station F 81 südwärts in der Ostsee kommen in den Planktonproben 4 bis 8 Arten vor: meistens sind diese Zahlen 5 oder 6 .

In den Benthosproben finden sich wieder viel mehr Arten und Varietäten. So sind in der Probe bei Station "16" im Plankton 7 Formen und im Benthos sogar 53 Formen oder 46 Formen meln als im Planliton zu beobachten. Abb. 13 zeigt sehr übersichtlich, dass zwischen den Diatomeenfloren im Plankton und am Meeresboden an denselben Stellen sehr grosse Unterschiede bestehen und dass diese Floren nicht miteinander vergleichen werclen können. 


\section{Zusammenfassung}

Die Planktondiatomeenflora in der Ostsee sowie im Finnischen und im Bottnischen Meerbusen war sehr arten- und varietätenarm. Gewöhnlich romnten in den Proben bei jecler Station nur 3 bis 11 Formen gefunden

Die Salzkonzentration schwankte im Oberflächenwasser zwischen 2.63 $\%$ und $7.79 \%$ und am Meeresboden zwischen $3.90 \%$ und $15.25 \%$, und clie Diatomeenflora war von diesen Unterschieden in der Salzkonzentration abhängig.

Bei den methodischen Untersuchungen ist festzustellen gewesen, dass bei oberflächlichen Untersuchungen der Diatomeenpräparate die Fehler recht gross gewesen sind. Man kann dadurch sogar falsche Vorstellungen von der Diatomeenflora gewinnen, denn viele Arten bleiben aus.

Im Untersuchungsgebiet traten hauptsächlich Salz- und auch Brackwasserdiatomeen auf, von denen Salzwasserformen in der Otsee und Brackwasserformen wiederum im Bottnischen und im Finnischen Meerbusen verbreitet waren.

Von den vielen Diatomeen kamen nur Thalassiosira baltica, Actinocyclus ehrenbergii, Achnanthes taeniala, Chaetoceros boreatis und Cocconeis scutellum beinahe in allen Teilen des Untersuchungsgebietes reichlich vor. 


\section{Literaturverzeichnis}

Avruvidius, C. W. S., 1896, Das Plankton des Baltischen Meeres. Bih. K. Svenska Vet. Akad. Hancll., 21: 4, 8 .

Buch, K. 1 . Gripenberg. Stina, 1938, Jahreszeiblicher Verlauf der chemischen und biologischen Faktoren im Meerwasser bei Hangö im Jahre 1935. Merentutkimuslaitoksen julkaisuja, 118, p.1-26.

C'Leve, P. T., 1891, The Diatoms of Finland. Acat. Soc. F. Fl. Fenn. 8: 2, p. 1-68.

Cleve-Euler, A., 1911, Das Bacillariaceen-Plankton in Gewässern bei Stockholın. (Vorlüufige Mitteilung). Arch. f. Hydrobiol.

- - 1942, Coscinodisci et Thalassiosirae Tennosueciae. Bot. Not. Lund.

Grasprist, G., 1938, Zur Kenntnis der 'Temperatur und des Salzgelaaltes des Baltischen Meeres an den Küsten Finnlands, Diss., Helsinki, Femnia. 65, Ni. 2, p. $1-166$.

HalMe, E.. 1944, Planktologische Untersuchungen in der Pjo-Bucht und angrenzen. clen Gewässern. I. Milieu und Gesamtplankton. Ann. Zool. Soc. Vanamo. 10:2, p. $1-180$.

Juhlin-Danafelt, H., 1882, On the Diatoms of the Baltic Sea. Bih. K. Sr. Yet.-Ak. Handl., 6, n:o 21, p. 1-5:.

Korolerf, F, 1959, The Baltic cruise with R/V Aranda 1958. Hyclrographical data. Merentutlsimuslaitoksen julkaisu n:0 193.

Leegatrd, Caroline, 1920, Microplankiton from the Finnish waters during the month of May 1912. Acta. Soc. Scient. Fenn. 48: 5, p. 1-44.

Leyander, K. M., 1915. Zur Kenntnis der Bodenfauna und des Planktons der Pojowiek. Fenuia 35: 2, p. 1-39.

Mölder, K.. 1943 a, Studien über die Ölsologie und Geologie der Boclencliatomeen in der Pojo-Bucht. Ann. Bot. Soc. Yanamo. 12: 2, p. 1-204. (auch Bull. Comm. géol. cle Finlande. 127, p. 1-204).

-" - 1943 b, Rezente Diatomeen in Finnland als Grundlage quartärgeologiseher Untersuchungen. Gicol. der Meere und Binnengew, 6, p. 148-240.

—- Halme, E. und Mölder, K, 1958, Planktologische Untersuchungen in der Pojo-Bucht und angrenzenden Gewässern. III. Ann. Bot. Soc. Vanamo. 30: 3, p. $1-71$.

Sichulz, P., 1926, Die Kieselalgen der Danziger Bucht. Bot. Arch. 13: 3-4, p. 149-327.

- - 1928, Süss- und Brackwasserdiatomeen aus dem Gebiete der Freien Stadt Danzig und dem benachbarten Pommerellen. Ber. Westppr. Bot.-Zool. Ver. 50, p. $85-195$.

Srmovisin, R., 1959, Neue Diatomeen aus der Ostsee I. Kieler Meeresforschungen. 15: 1, p. $74-83$.

-〉- 1960. Neue Diatomeen aus der Ostsee II. Tbid., 16: 1. p. 126--130.

$8351-62$ 
